\title{
Sex Differences in Cognitive Flexibility and Resting Brain Networks in Middle-Aged Marmosets
}

\author{
M. LaClair, ${ }^{1,2}$ M. Febo, ${ }^{3}$ B. Nephew, ${ }^{4,7}$ N.J. Gervais, ${ }^{5,6}$ G. Poirier, ${ }^{7}$ K. Workman, ${ }^{6}$ S. Chumachenko, ${ }^{7}$ L. \\ Payne, ${ }^{7}$ M.C. Moore, ${ }^{7}$ J.A. King, ${ }^{4,7}$ and ${ }^{10}$ A. Lacreuse ${ }^{1,5,6}$
}

https://doi.org/10.1523/ENEURO.0154-19.2019

\begin{abstract}
${ }^{1}$ Neuroscience and Behavior Program, University of Massachusetts, Amherst, MA 01003, ${ }^{2}$ Department of Psychology, Fairfield University, Fairfield, CT 06824, ${ }^{3}$ Department of Psychiatry, University of Florida, Gainsville, FL 32610, ${ }^{4}$ Worcester Polytechnic Institute, University of Massachusetts Medical School, Worcester, MA 01655, ${ }^{5}$ Center for Neuroendocrine Studies, University of Massachusetts, Amherst, MA 01003, ${ }^{6}$ Psychological and Brain Sciences, University of Massachusetts, Amherst, MA 01003, and ${ }^{7}$ Center for Comparative Neuroimaging, University of Massachusetts Medical School, Worcester, MA 01655
\end{abstract}

\begin{abstract}
Sex differences in human cognitive performance are well characterized. However, the neural correlates of these differences remain elusive. This issue may be clarified using nonhuman primates, for which sociocultural influences are minimized. We used the marmoset (Callithrix jacchus) to investigate sex differences in two aspects of executive function: reversal learning and intradimensional/extradimensional (ID/ED) set shifting. Stress reactivity and motor function were also assessed. In agreement with human literature, females needed more trials than males to acquire the reversals. No sex differences in ED set shifting or motivational measures were observed. The findings suggest enhanced habit formation in females, perhaps due to striatal estrogenic effects. Both sexes showed increased urinary cortisol during social separation stressor, but females showed an earlier increase in cortisol and a greater increase in agitated locomotion, possibly indicating enhanced stress reactivity. Independent of sex, basal cortisol predicted cognitive performance. No sex differences were found in motor performance. Associations between brain networks and reversal learning performance were investigated using resting state fMRI. Resting state functional connectivity ( $\mathrm{rSFC}$ ) analyses revealed sex differences in cognitive networks, with differences in overall neural network metrics and specific regions, including the prefrontal cortex, caudate, putamen, and nucleus accumbens. Correlations between cognitive flexibility and neural connectivity indicate that sex differences in cognitive flexibility are related to sex-dependent patterns of resting brain networks. Overall, our findings reveal sex differences in reversal learning, brain networks, and their relationship in the marmoset, positioning this species as an excellent model to investigate the biological basis of cognitive sex differences.
\end{abstract}

\section{Significance Statement}

We examined sex differences in multiple outcomes [cognition, motor function, stress reactivity, and resting state functional connectivity (rsFC)] in middle-aged marmosets. We found that female marmosets had poorer reversal learning relative to males. rsFC analyses revealed substantial sex differences in cognitive networks, with differences in both overall neural network metrics and specific regions, including the prefrontal cortex, caudate, putamen, and nucleus accumbens. Sex-dependent correlations between reversal learning and neural connectivity measures indicate that the sex difference in cognitive performance is related to sex-dependent patterns of resting brain networks. Although these data are correlational and cannot determine causal effects, they are consistent with human resting state data, supporting the idea that cognitive sex differences have identifiable intrinsic neural correlates. 
Key words: animal models; cognitive flexibility; executive function; resting state functional connectivity; reversal learning; sex differences

\section{Introduction}

Sex and gender differences in cognitive performance are an actively debated topic, both in the public domain and the scientific community. The American Community Survey performed by the United States Census Bureau in 2011 found underrepresentation of women in science, technology, engineering, and math (STEM) fields, with men representing $74 \%$ and women $26 \%$ of STEM workers, despite women outperforming men overall in higher education (Flashman, 2013). With increased focus on gender disparities in STEM comes greater interest in the biological factors that impact sex-based differences in cognitive performance.

In humans, sex differences in certain cognitive domains are well established (Kimura, 1992; Halpern, 2000; Hampson, 2002). Men outperform women on many spatial tasks, including mental spatial rotation (Voyer et al., 1995), while women outperform men on verbal tasks such as verbal fluency (Heinzel et al., 2013) and verbal memory (Munro et al., 2012; Murre et al., 2013). However, sex differences in cognitive performance may not be as clearcut as previous studies may have suggested, as culture and gender stereotypes are known to impact performance on selective cognitive measures (Levine et al., 2005; Lippa et al., 2010; Miller and Halpern, 2014). Thus, sociological and biological influences are tightly intertwined in humans, highlighting the importance of studying appropriate animal models to understand the biological basis of cognitive sex differences.

We examined cognitive sex differences in the marmoset, a small $(300-500 \mathrm{~g})$ New World primate that is emerging as an attractive new primate model for neuroscience research (Okano et al., 2012; Miller, 2017; Prins

Received April 26, 2019; accepted June 18, 2019; First published July 1, 2019.

The authors declare no competing financial interests.

Author contributions: M.L. and A.L. designed research; M.L., N.J.G., K.W., L.P., and A.L. performed research; M.L., M.F., B.N., N.J.G., G.P., S.C., M.C.M., J.A.K., and A.L. analyzed data; M.L., M.F., B.N., N.J.G., and A.L. wrote the paper.

This study was supported by the National Institutes of Health Grant AG 046266 (to A.L.), a dissertation fellowship from the UMass Center for Research on Families (CRF; M.L.), and the National Institute of Health Grant S10 OD018132 (to J.A.K.). M.F. was supported from the National High Magnetic Field Laboratory's Advanced Magnetic Resonance Imaging \& Spectroscopy (AMRIS) Facility (National Science Foundation Cooperative Agreement DMR1157490 and the State of Florida).

Acknowledgements: We thank Dr. Afonso Silva for providing methodological details for the marmoset imaging helmets and cradle, Dr. Aline Sayer and the CRF for statistical consultation, Dr. Jeffrey French for the hormonal assays, and Dr. Omar Touzani for providing methodological details regarding the hill and valley task. We also thanks are the UMass Psychology Shop for building the apparatuses, to all the students who participated in data collection, and to the excellent assistance of the UMass Animal Care staff.

Correspondence should be addressed to M. LaClair at mlaclair@fairfield.edu or A. Lacreuse at alacreuse@psych.umass.edu.

https://doi.org/10.1523/ENEURO.0154-19.2019

Copyright (C) 2019 LaClair et al.

This is an open-access article distributed under the terms of the Creative Commons Attribution 4.0 International license, which permits unrestricted use, distribution and reproduction in any medium provided that the original work is properly attributed. et al., 2017). Marmosets share with other primates a complex brain and behavior but, because of their small size, present a number of practical advantages as laboratory animals. They also have a relatively short lifespan of $\sim 10$ years, which is advantageous for developmental research. The marmoset has a lissencephalic brain approximately five times larger than the rat brain. Although it is 12 times smaller than the rhesus monkey brain and 180 times smaller than the human brain (Solomon and Rosa, 2014), brain organization is well conserved among the three primate species (Chaplin et al., 2013). Marmosets can successfully perform a range of prefrontal-dependent tasks (Miles, 1957; Ridley et al., 1981; Lacreuse et al., 2014; LaClair and Lacreuse, 2016) and hippocampaldependent tasks (Lacreuse et al., 2014). Little is known about sex differences in cognition in this species. One study conducted in 35 young marmosets (one to four years old) found no sex difference in the performance of visual discriminations and reversal tasks (Takemoto et al., 2015).

The second goal of this research was to investigate the neural correlates of cognitive sex differences in the marmoset using resting state functional connectivity (rsFC) with $\mathrm{fMRI}$. rsFC exploits the $\mathrm{fMRI}$ signal to characterize temporally correlated fluctuations in neuronal activity when subjects are at rest. In humans, variations in rsFC have been associated with differences in cognitive performance (Sala-Llonch et al., 2012; Zou et al., 2013). In addition, sex differences in cognition have been reported to be associated with sex differences in brain networks (Ingalhalikar et al., 2014; Satterthwaite et al., 2015; Tunç et al., 2016). Marmosets can be trained to undergo conscious neuroimaging with minimal acclimation (Liu et al., 2013). Several studies have revealed four higher-order functional connectivity networks in marmosets that are similar to those found in humans (Belcher et al., 2013, 2016); however, the effects of sex on functional connectivity have not yet been examined in this species.

As in prior marmoset resting state fMRI studies (Liu et al., 2019) our objective was two-fold: (1) determine the organization of global functional connectivity in male and female marmosets, and (2) determine the relationship between cognitive behaviors and metrics reflecting functional connectivity patterns brain-wide. Our rationale for this approach was that cognitive behaviors investigated here emerge from neural activity and functional interactions of many distributed brain areas. Using network science metrics offers a unique way to test this hypothesis, which involves a broad number of brain regions. However, we should note that we did not have a priori predictions on the role of specific regions of interest ( $\mathrm{ROIs}$ ) in the orbitofrontal cortex (OFC)/striatum.

The present study compared the performance of middle-aged male and female marmosets (approximately five years of age) on tasks of executive function, including cognitive flexibility and attentional set shifting. To obtain a comprehensive understanding of factors impacting cog- 
Table 1. Characteristics of study subjects: sex, date of birth, and age at test

\begin{tabular}{|c|c|c|c|c|c|c|}
\hline Animal ID & Sex & DOB & $\begin{array}{l}\text { Age at start of } \\
\text { cognitive testing }\end{array}$ & $\begin{array}{l}\text { Age at social } \\
\text { separation }\end{array}$ & $\begin{array}{c}\text { Age at motor } \\
\text { testing }\end{array}$ & $\begin{array}{c}\text { Age at rsFC } \\
\text { imaging }\end{array}$ \\
\hline 02 & Female & $9 / 16 / 10$ & 5.82 & 5.52 & 5.49 & 6.52 \\
\hline 04 & Female & $9 / 16 / 10$ & 5.32 & 5.59 & 5.41 & 6.56 \\
\hline 06 & Female & $7 / 5 / 11$ & 4.93 & 4.67 & 4.68 & 5.64 \\
\hline 08 & Female & $1 / 4 / 10$ & 6.05 & 6.16 & 6.09 & 7.32 \\
\hline 10 & Female & $7 / 5 / 11$ & 4.52 & 4.81 & $\mathrm{~N} / \mathrm{A}$ & 5.93 \\
\hline 12 & Female & $3 / 22 / 11$ & 4.82 & 5.01 & 4.95 & 5.76 \\
\hline 14 & Female & $11 / 23 / 11$ & 4.12 & 4.36 & 4.26 & $\mathrm{~N} / \mathrm{A}$ \\
\hline 15 & Female & $1 / 18 / 11$ & 4.99 & 5.21 & 5.14 & 6.45 \\
\hline 17 & Female & $4 / 2 / 12$ & 4.21 & 4.01 & 4.07 & 5.53 \\
\hline 19 & Female & $1 / 6 / 12$ & 4.78 & 4.25 & 4.35 & $\mathrm{~N} / \mathrm{A}$ \\
\hline 21 & Female & $11 / 18 / 11$ & 4.72 & 4.71 & 4.47 & 5.61 \\
\hline 23 & Female & $4 / 28 / 12$ & 4.08 & 3.96 & 3.96 & 5.13 \\
\hline 26 & Female & $3 / 18 / 12$ & 4.41 & 4.34 & 4.44 & 5.70 \\
\hline 28 & Female & $3 / 28 / 12$ & 4.55 & 4.34 & N/A & N/A \\
\hline 01 & Male & $6 / 1 / 11$ & 4.64 & 4.87 & 4.78 & 5.82 \\
\hline 03 & Male & $6 / 18 / 10$ & 5.56 & 5.73 & 5.72 & 6.81 \\
\hline 05 & Male & $5 / 1 / 11$ & 4.69 & 4.86 & 4.84 & 5.81 \\
\hline 07 & Male & 9/3/09 & 6.86 & 6.51 & 6.48 & 7.65 \\
\hline 09 & Male & 8/20/10 & 5.52 & 5.57 & 5.52 & 6.80 \\
\hline 11 & Male & $10 / 28 / 10$ & 5.21 & 5.39 & 5.27 & 6.15 \\
\hline 13 & Male & $11 / 28 / 11$ & 4.65 & 4.64 & $\mathrm{~N} / \mathrm{A}$ & $\mathrm{N} / \mathrm{A}$ \\
\hline 16 & Male & $5 / 13 / 12$ & 3.96 & 3.92 & N/A & 5.13 \\
\hline 18 & Male & $5 / 10 / 11$ & 5.30 & 4.93 & 5.01 & 6.42 \\
\hline 20 & Male & $4 / 8 / 11$ & 5.21 & 5.04 & 5.05 & $\mathrm{~N} / \mathrm{A}$ \\
\hline 22 & Male & $6 / 4 / 11$ & 5.01 & 4.88 & 4.93 & 6.07 \\
\hline 24 & Male & $11 / 9 / 11$ & 4.77 & 4.41 & 4.42 & 5.59 \\
\hline 25 & Male & $8 / 4 / 11$ & N/A & 5.06 & N/A & N/A \\
\hline 27 & Male & $9 / 28 / 11$ & 5.03 & 4.81 & 4.92 & 6.17 \\
\hline
\end{tabular}

N/A indicates animal did not complete test.

nitive performance, we also investigated sex differences in motor performance and stress reactivity. Following behavioral tasks, monkeys were scanned for rsFC to investigate sex differences in brain networks and their potential relationship to cognitive function.

\section{Materials and Methods}

\section{Subjects}

Twenty-eight marmosets ranging from four to six years old were used for this study ( 14 females, mean age $=4.81$ years; 14 males, mean age $=5.10$ ). All marmosets were housed in male/female pairs at the University of Massachusetts, Amherst and maintained under a 12/12 h light/ dark cycle (lights on at 7:30 A.M.) at an ambient temperature of $80 \mathrm{~F}$ with a relative humidity of $50 \%$. The pairs were housed in steel mesh cages $(101 \times 76.2 \times$ $78.7 \mathrm{~cm}$ ) equipped with perches, hammock, nest boxes, and branches to encourage species-typical behaviors. Male marmosets were vasectomized in adulthood, before the start of the study, to avoid pregnancy. The characteristics of the marmosets and the tests they performed can be seen in Table 1. The monkeys were fed a daily diet of fresh food including fruits, vegetables, nuts and seeds, various breads, and ZuPreem marmoset food. Fruit and nuts were provided twice daily up until $2 \mathrm{~h}$ before and immediately after cognitive testing and water was available ad libitum. The monkeys were provided with daily enrichment, including foraging tubes and a variety of toys. The animals were cared for in accordance with the guide- lines published in the Guide for the Care and Use of Laboratory Animals, 8th edition (2011). The studies were approved by the Institutional Animal Care and Use Committee of the University of Massachusetts Amherst and the University of Massachusetts Medical School, Worcester.

\section{General procedure}

Monkeys received comprehensive assessments of cognitive function, stress reactivity and motor function. The details regarding each assessment are provided below. Monkeys were trained on cognitive tasks $5 \mathrm{~d}$ per week, with training spanning several months. Tests of motor function were conducted concurrently at times when the monkeys were not engaged in cognitive testing. The social separation task was conducted on a single day during which monkeys were not engaged in any other task.

\section{Cognitive assessments}

Monkeys were tested on the Cambridge Neuropsychological Test Automated Battery (CANTAB), an automated cognitive testing battery used with humans (Robbins et al., 1994), and nonhuman primates (NHPs), including marmosets (Roberts et al., 1988; Spinelli et al., 2004).

\section{Testing apparatus}

The nonhuman primate version of the CANTAB (Monkey CANTAB Intellistation with Liquid Reward, Model $80951 \mathrm{~A})$ consisted of a touch screen panel $(37.78 \mathrm{~cm})$ in a stainless-steel frame $(56 \times 38 \times 30 \mathrm{~cm})$ using an 
A Simple Discriminations and Simple Reversals Pairs (Reversal Learning)

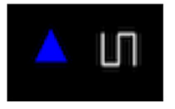

$\mathrm{SD} 1 / \mathrm{SR} 1$

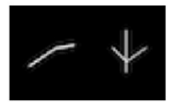

$\mathrm{SD} 2 / \mathrm{SR} 2$

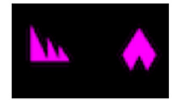

SD3/SR3
Compound Discriminations and Compound Reversals Pairs (ID/ED)

B

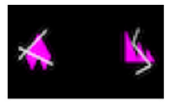

CD1/CR1

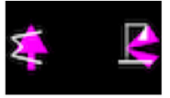

$\mathrm{CD} 2 / \mathrm{CR} 2$

Intradimensional

Shift/Reversal

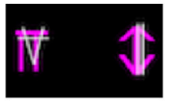

CD3/CR3

xtradimensiona Shift/Reversal
Figure 1. Examples of stimuli from SR learning $(\boldsymbol{A})$ and from the ID/ED (B).

Intel-based 1.6-GHz CPU operating system. A stainlesssteel sipper tube in the middle of the screen delivered the reward (banana milkshake) via a peristaltic pump, at a rate of $0.2 \mathrm{ml} / \mathrm{s}$.

\section{Procedure}

To encourage participation, food and water were removed from the animals' cages $2 \mathrm{~h}$ before testing and replaced in the cage no later than $5 \mathrm{~h}$ after removal. For testing, marmosets voluntarily entered a transport box $(34.1 \times 20.65 \times 30.8 \mathrm{~cm})$ made of clear Plexiglas attached to the front of their homecage. This set-up allowed the focal animal to have visual, auditory, and olfactory access to their partner, as well as other animals in the colony. The CANTAB was positioned against the meshed front $(2.5 \times 2.5 \mathrm{~cm}$ openings) of the transport box, so animals could reach through to touch the screen and lick the reward from the sipper tube. Experimenters loaded CANTAB testing programs remotely from a desktop computer located outside of the marmoset housing rooms.

\section{CANTAB training}

We followed the procedures described by Roberts et al. (1988) and Pearce et al. (1998) for stages of tonereinforcement associations and touch-training. Monkeys were trained to lick the milkshake from the spout, to associate a tone $(41 \mathrm{~Hz})$ with reward delivery (5 s), to touch the screen, touch a large static square at the center of the screen and touch smaller squares appearing successively at random locations on the screen, before being presented with the first pair of stimuli.

\section{Simple reversal (SR) learning}

The marmosets were presented with a total of three pairs of stimuli depicted in Figure $1 A$. The first pair of stimuli consisted of a blue triangle and a white line. The second pair consisted either of two different white lines or two different pink shapes (the order of presentation of pairs 2 and 3 was counterbalanced between monkeys). For each pair, monkeys had to perform a simple discrimination (SD), followed by a SR. The two stimuli appeared in any position on the touch screen. Animals began with $\mathrm{SD}$, pair 1 and were given a total of 40 trials a day, $5 \mathrm{~d}$ a week, to learn the stimulus/reward contingencies (for ex- ample, blue triangle always rewarded). Once animals reached a $90 \%$ correct criterion out of 40 consecutive trials, the stimulus/reward contingencies were reversed (e.g., the white line was now rewarded; SR pair 1). When the $90 \%$ accuracy criterion was reached on the SR, the marmoset moved on to a new stimulus pair (i.e., SD pair 2). The number of trials to reach the $90 \%$ learning criterion (TTC) were recorded, with fewer trials reflecting faster learning of the stimulus/reward contingencies. In addition, the number of omissions (trials on which the monkey made no choice) and the response times (RTs) on each trial were recorded as an index of motivation. To facilitate analyses between reversal learning performance and rsFC, a composite of performance, the reversal index (RI) was computed for each monkey by dividing the mean TTC across the three reversals (SR1, SR2, SR3) by the mean TTC on the three SDs (SD1, SD2, SD3). This composite score reflected how many more trials the monkey had needed to perform the reversals relative to pre-reversal discriminations, with a higher ratio reflecting poorer performance. As noted early by Rumbaugh and Jeeves (1966) such a ratio provides a better measure of reversal learning per se, by overcoming individual differences (in perception, anxiety, motor function) in discrimination abilities.

\section{Intradimensional/extradimensional (ID/ED) set shifting}

For the ID/ED, the marmosets were again presented with a total of three pairs of stimuli, however, each was a compound stimulus, consisting of a shape dimension and a line dimension, overlaid on top of one another (Fig. 1B). For the first discrimination (CD1) animals were given the exact same stimulus/reward contingencies as SR3 (e.g., same shapes and same rewarded stimulus as SR3), but with the addition of an extraneous dimension (lines) that they needed to ignore. It was followed by a reversal (CR1) in which they had to select the alternate shape of the pair. Animals were given 40 trials per day and were required to reach a $90 \%$ accuracy criterion to move on to the next stage of testing.

\section{Intradimensional shift (pair 2)}

the second pair of stimuli was made from new stimuli, but the target dimension (e.g., shape) from CD1/CR1 continued to apply and the other dimension (lines) was to be ignored.

\section{Extradimensional shift (pair 3)}

the final pair were new stimuli, but this time monkeys had to switch from using the previous target dimension (e.g., shape), to using the alternate dimension (e.g., line) as the target.

\section{Statistical analysis}

For SR learning, the TTC, errors to criterion, omissions, $\mathrm{RT}$, and RI were analyzed using a mixed ANOVA with sex as a between-subjects factor and pair number (pair 1, pair 2, pair 3) and test type (SD, SR) as within-subjects factors. The same analysis was used for the ID/ED shifting task, with the TTC, errors to criterion, omissions, and RTs as variables. 


\section{Social separation}

In NHPs that form social bonds, mate separation can trigger robust hypothalamic-pituitary-adrenals (HPA) activation and behavioral indications of stress (Cross et al., 2004). Social separation has been used as a stressor in a number of NHP species, including the marmoset. We used the procedure described by French et al. (2007). Following urine collection (see Urine collection and assays section), the focal animal entered a transport box and was immediately transferred from its colony room to a similar cage in an empty room. Separated animals had access to food and water ad libitum. Animals were reunited with their cage mates at 15:30, after $7 \mathrm{~h}$ had elapsed. No cognitive testing occurred for the animal undergoing social separation on the day of separation.

\section{Behavioral observations}

Behavior was video-recorded with a SONY Handycam (HDD 2000× digital zoom) video camera provided with $0.45 \times$ wide angle lens. Animals were video-recorded at baseline (BL, $30 \mathrm{~min}$ before separation, 8:30 A.M.), throughout the separation period (Sep), and $24 \mathrm{~h}$ postseparation (Post-Sep; the day following separation, 8:30 A.M.). Behavior was scored from the video recordings using an interval schedule of $15 \mathrm{~s}$, with behaviors occurring $0-20$ times within a 5 -min behavioral sample. All experimenters achieved $90 \%$ interrater reliability on behavioral observations before scoring videos. Behaviors included measures of locomotion, sociality, and aggression, adapted from an extensive ethogram developed for the marmoset (Stevenson, 1977). Behavior during the separation was scored as follows: t1 (first $5 \mathrm{~min}$ after experimenter left separation room), t2 (5-min sample $3.5 \mathrm{~h}$ after start of separation), and t3 (final 5-min sample of the 7-h separation). Behaviors from the three time points were then averaged to create an overall separation score.

\section{Urine collection and assays}

Urine samples were collected to assess cortisol levels in each animal immediately before separation (BL) and the morning following separation (Post-Sep), using a method described by Saltzman et al. (2004). Briefly, animals entered the transport box at 7:30, a few minutes after the lights turned on, and remained there until they urinated or until $30 \mathrm{~min}$ had elapsed. During the 7-h separation, experimenters entered the separation room once each hour and collected any available urine from a catch pan underneath the animal's cage. Urine was pipetted into $1.5-\mathrm{ml}$ vials, spun for $5 \mathrm{~min}$ and then frozen at $-20^{\circ} \mathrm{C}$. The Endocrine BioServices Assay Lab at the University of Nebraska Omaha, performed all urinary cortisol assays. Because of the variability in urine availability, urine samples were grouped as follows: averaged samples from hours 1 and 2 of separation (onset), averaged samples from hours 3,4 , and 5 (mid), and averaged samples from hours 5 and 6 (end). However, because too few urine samples were available in the first $2 \mathrm{~h}$ of the separation period, only the samples from the mid and end periods were included in the analyses.

\section{Statistical analysis}

Behavior and urinary cortisol were analyzed using a mixed ANOVA with sex as a between-subjects factor and

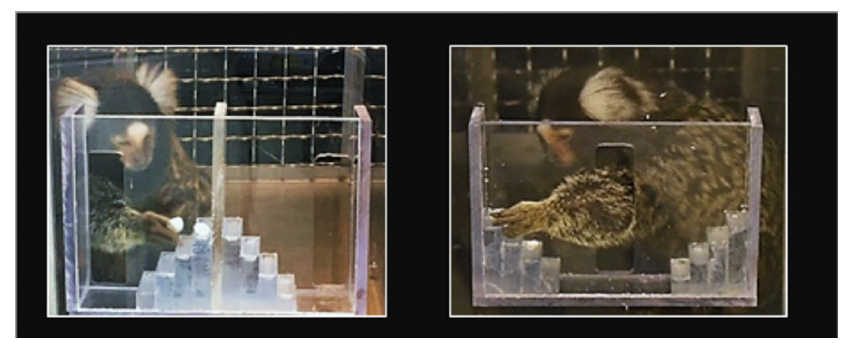

Figure 2. Picture of the hill and valley apparatus.

test phase as a within-subjects factor. The analysis of behaviors focused on locomotor behaviors, as locomotion is a useful indicator of stress, previously shown to be altered by social separation in marmosets (Johnson et al., 1996). We recorded instances of agitated locomotion (defined as an animal moving more than one step in a directed plane, with an exaggerated gait, sometimes accompanied by piloerection, with tail extended or arched) and calm locomotion (defined as animal moving more than one step in a directed plane with a relaxed gait), with increased agitated locomotion being indicative of increased stress (Badihi et al., 2008). Correlations between behavior and change in cortisol from baseline to end (change $=$ end-BL) were also performed.

\section{Motor task}

To assess motor function, we used the hill and valley task, a measure of fine motor ability that has previously been used in marmosets, especially in models of stroke and Parkinson's disease (Eslamboli et al., 2003; Marshall et al., 2003; Bihel et al., 2010; Phillips et al., 2017). It assesses motor function in each limb as well as perceptual spatial impairment. The monkeys were tested in their housing room. As for the cognitive tasks, monkeys voluntarily entered a transport box attached to their home cage to access the hill or valley apparatus, securely attached to the front of the box via a Plexiglas screen (Fig. 2). Each apparatus had two five-step $(9 \times 9 \times 3 \mathrm{~mm})$ staircases, either rising away from a central opening (valley), or from two lateral openings (hill). The monkeys had to reach through these openings, using either their right or left hand, to retrieve one of the mini dehydrated marshmallows (6 $\mathrm{mm}$ in diameter) placed in the middle of each step. In the valley version, the central vertical slot $(7.7 \times 2 \mathrm{~cm})$ allowed the marmoset to use its left hand to reach the reward located on its right, or the right hand to reach the reward located on its left (contralateral hemifield to hand used). In the hill version, entry was through two lateral slots $(7.4 \times 2 \mathrm{~cm})$ on the side of each stair so that the monkey had to use its right hand to retrieve the rewards on the right stairs and the left hand to retrieve the rewards on the left stairs (ipsilateral hemifield to hand used).

Marmosets were trained on the hill and valley apparatus until they successfully retrieved a marshmallow from each step with each hand. If the marmoset failed to perform the task after 10 attempts, it was excluded from the task. For testing, marmosets were given a maximum of $5 \mathrm{~min}$ to retrieve all five marshmallows from one staircase of the apparatus. Each marmoset received four conditions (hill 
left, hill right, valley left, valley right) per session, one session per day, and performed a total of three testing sessions. The order of the hill and valley conditions was randomized (half received hill first, half valley first) and alternated each test day. If the marmoset failed to retrieve the five marshmallows within the 5-min time limit, the test session was rerun the following day. Marmosets received one point for retrieving the marshmallow on the first step, two points for retrieving from the second step, and so on, for a maximal accuracy score of 15 points per hand. Marmosets lost one point each time a marshmallow was dropped. The time to retrieval from the first reaching through the opening until retrieval of the last marshmallow was recorded for each condition.

\section{Hand preference}

Because hand preference had the potential to affect the ability of each hand, we determined the hand preference of each marmoset using a simple hand reaching task. Monkeys performed 50 reaches through the central slot of the valley apparatus to reach a mini marshmallow placed $7.7 \times 2 \mathrm{~cm}$ from the slot. The number of left and right hand reaches was recorded. Any trials in which the marmoset used both hands were excluded. For each subject, a handedness index $(\mathrm{HI})$ was determined by subtracting the number of left-handed responses from the number of right-handed responses and dividing by the total number of responses (Hopkins, 1999). HI values ranged from -1.0 to 1.0 , with the absolute value representing the strength of the preference. The positive values indicated a right-hand bias while the negative values indicated a left-hand bias.

\section{Statistical analysis}

Mixed measures ANOVAs were performed on the Time to retrieval and accuracy scores, with sex as betweensubjects factor and hand used as a within-subjects factor, and $\mathrm{HI}$ as a covariate.

\section{rsFC}

We used the state-of-the-art technique developed by Dr. Afonso Silva (Silva et al., 2011), to image awake marmosets without the use of anesthetic. Each animal wore a sleeveless jacket (Lomir Biomedical, Inc), which attached to a semi-cylindrical plastic cover made of Lexan, restricting anterior or posterior movement but allowing the animal to move its arms, legs, and tail freely. The plastic cover was attached to the back of the marmoset's jacket using plastic cable ties. The monkey laid in a prone, sphinx position, in the MRI bed, which consisted of a 111-mm cylindrical tube. The cover was secured to the bed by screwing nylon thumb screws into the bars on the bed. Each marmoset wore an individualized helmet adapted to their skull to support the head and prevent movement while providing comfort.

\section{Acclimation}

Before imaging sessions, animals were acclimated to the bed restraint device, noise related to imaging, and the helmet, following the procedures detailed in Silva et al. (2011). The entire acclimation period took between four and six weeks for each animal, with acclimation occurring 4-5 d a week.

\section{fMRI data acquisition}

The monkeys were scanned at the Center for Comparative Neuroimaging at the University of Massachusetts Medical School. Following $1 \mathrm{~h}$ acclimation to the neuroimaging room, marmosets were placed in jackets, arranged in the imaging cradle, positioned in the MRI bed, and imaged using a custom head coil as described in Silva et al. (2011). Imaging was conducted on a high-field MRI system. The system incorporated a $4.7 \mathrm{~T} / 40 \mathrm{~cm}$ horizontal magnet (Oxford) equipped with $450 \mathrm{mT} / \mathrm{m}$ magnetic field gradients and a $20-\mathrm{G} / \mathrm{cm}$ magnetic field gradient insert (inner diameter $=11.5 \mathrm{~cm}$; Bruker) with a digital interface to Bruker console, run by Paravision 6. Field map measurements allowed the estimation of the magnetic field inhomogeneity and shimming. For each marmoset, anatomic images were obtained using rapid acquisition relaxation enhanced (T2 Turbo RARE) sequence with relaxation time $(T R)=2892.968 \mathrm{~ms}$, RARE factor $=8$, echo time $(T E)=36 \mathrm{~ms}$, resolution matrix $=$ $256 \times 256$, field of view $(F O V)=45 \mathrm{~mm} \times 45 \mathrm{~mm}$, slice number $=25$, slice thickness $=1.1 \mathrm{~mm}$. Functional images were acquired using echo-planar imaging (EPI) with the same FOV and slice thickness, TR $=1691.038 \mathrm{~ms}$, TE $=26.523 \mathrm{~ms}$, flip angle $=90^{\circ}$, and resolution matrix $=$ $128 \times 128$, for $11.27 \mathrm{~min}$ (400 repetitions). All monkeys were scanned within three months of cognitive testing.

\section{rsFC image processing}

Brain masks were first generated using FMRIB Software Library's (FSL) Brain Extraction Tool (BET; Smith, 2002) on anatomic scans and masks were then manually adjusted with the help of ITKSNAP (www.itksnap.org). The masks outlining the brain were used to remove nonbrain voxels. The cropped brain images were aligned with a Marmoset brain template (Liu et al., 2018) using the FSL linear registration program FLIRT (Jenkinson et al., 2002). Registration matrices for each subject were saved and used to subsequently transform functional datasets into atlas space for preprocessing and analysis. Aside from subject-to-atlas registration, which used FSL FLIRT, postprocessing steps were conducted using Analysis of Functional Neurolmages (AFNI; Cox, 1996). AFNI's 3dDespike was used to remove time series spikes and this was followed by slice timing correction using $3 \mathrm{dTshift}$. Motion correction was conducted using $3 \mathrm{dvolreg}$, after which functional scans were aligned with the Marmoset template using FLIRT. Time series from motion estimates and from areas with CSF (CSF ventricles) and white matter were used as regressors. AFNl's 3dTproject was used for the removal of motion-related, CSF and white matter signals, spatial blurring (0.8 mm FWHM), and whole-brain voxel-wise bandpass filtering between 0.01 and $0.1 \mathrm{~Hz}$.

Time series $\mathrm{fMRl}$ signals from postprocessed scans were extracted from each ROI based on the atlas-guided seed location (122 bilateral placed seed regions included for 244 total ROIs). Time series for each voxel were averaged per ROI seed, exported as text files, and used voxel-wise cross-correlations were conducted to create correlation coefficient (Pearson's $r$ ) maps using AFNI 3dTcorr1D (Colon-Perez et al., 2016). Composite functional connectivity maps were generated using AFNI 3dT- 
Table 2. Mean TTC, sessions, omissions, errors, and response latencies for each sex

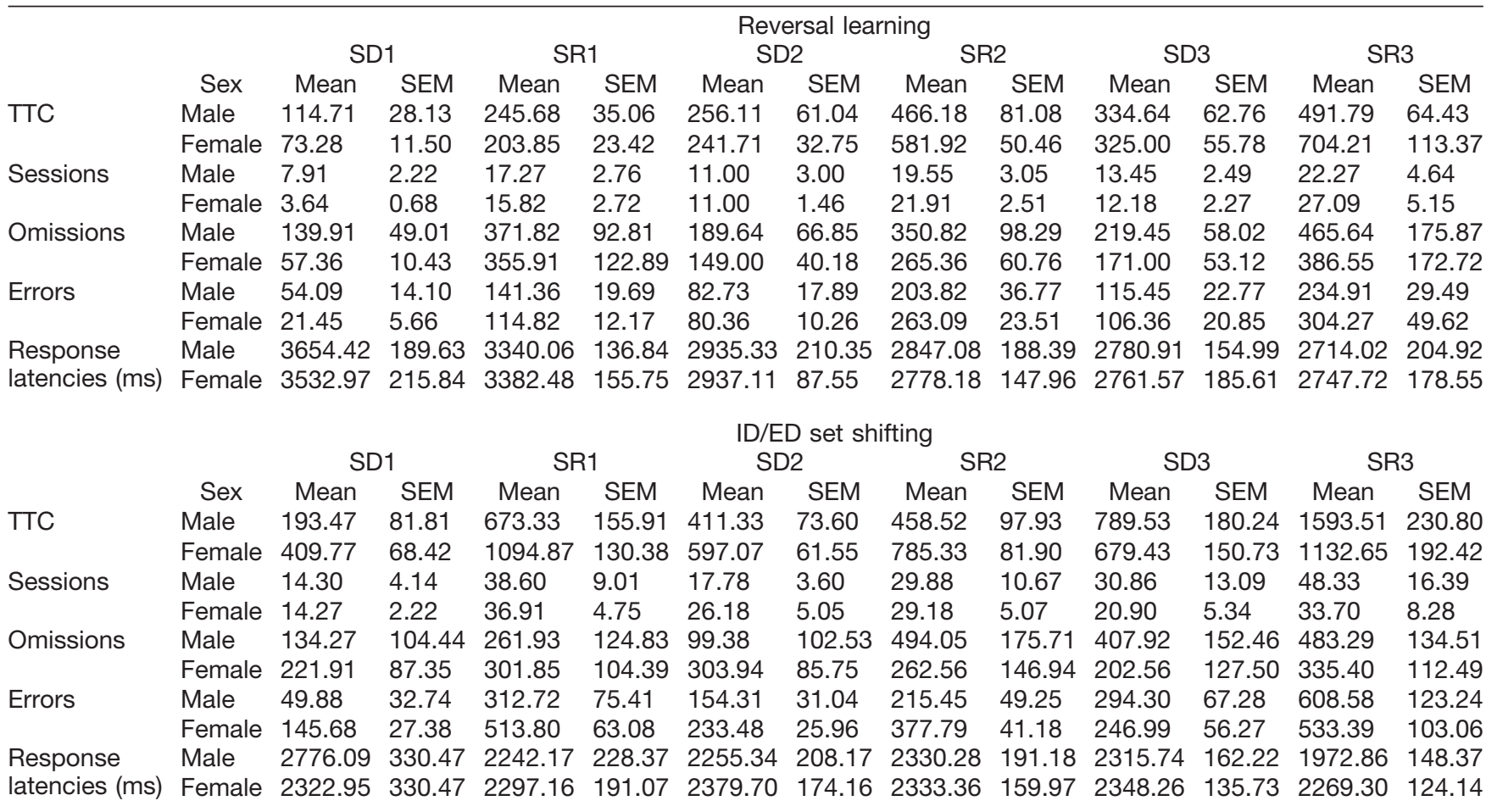

test ++ for cortical and subcortical seed regions to determine differences between male and female marmosets $(p<0.01)$. In addition, Pearson's $r$ coefficients per all $\mathrm{ROI}$ pairs were subjected to a voxel-wise z-transformation and exported for network analyses in MATLAB (MathWorks).

\section{Network analyses}

We calculated basic graph theory metrics to assess the topology of functional connectivity networks. Resting state $\mathrm{fMRI}$ data were analyzed using Brain Connectivity Toolbox for MATLAB (Rubinov and Sporns, 2010). Symmetrical connectivity graphs with a total 29,646 matrix entries were first organized in MATLAB (graph size $=n(n$ $-1) / 2$, where $n$ is the number of nodes represented in the graph, or $244 \mathrm{ROIs})$. The $z$ score values of the graphs were thresholded at various levels $(1 \%, 5 \%, 10 \%, 15 \%, 20 \%)$ for each subject to create matrices with equal densities before network metric assessments. Matrix $z$ values were normalized by the highest $z$ score, such that all matrices had edge weight values ranging from 0 to 1 . Node strength (sum of edge weights), clustering coefficient (the degree to which nodes cluster together in groups), average shortest path length (the potential for communication between pairs of structures), modularity (the degree to which the network may be subdivided into clearly delineated groups or communities), and small worldness (the degree to which functional brain networks deviate from randomly connected networks) were calculated for weighted or unweighted graphs (Newman, 2003; Newman and Girvan, 2004; Boccaletti et al., 2006; Saramäki et al., 2007; Humphries and Gurney, 2008).
The small world index was determined by comparing marmoset functional connectivity networks to an average of ten null hypothesis networks per monkey (Watts and Strogatz, 1998). Thus, the ratio for clustering coefficients and path lengths of marmoset brain relative to null networks were calculated. The ratio of clustering coefficients is known as $\gamma$, which for a small world network is larger than 1 (Humphries and Gurney, 2008). The ratio of average path length is referred to as $\boldsymbol{\lambda}$, which for a small world network is close to 1 . The small world (sw) parameter is the ratio of $\gamma / \lambda$, with a sw $>1$ indicative of small world topology (typical of real world networks) and sw $\sim 1$ indicative of a random network (Erdös and Rényi, 1960). Brain networks were visualized using BrainNet (Xia et al., 2013). The 3D networks were generated with undirected edges weights $E_{\text {undir }} \geq 0.2$. In these brain networks (or marmoset brain connectomes), the node size and color were scaled by the node strength, and edges were scaled by $z$ scores.

\section{Results}

\section{Cognitive tasks}

\section{SR learning}

Twenty-two monkeys (11 females, mean age $=5.05$ years, $\mathrm{SEM}=0.18 ; 11$ males, mean age $=4.69$, $\mathrm{SEM}=$ 0.14) completed the SR learning task (means for TTC, sessions, omissions, errors, and response latencies for each sex; Table 2). A significant interaction between sex and test type $\left(F_{(1,19)}=7.93, p=0.01\right.$, partial $\eta^{2}=$ $0.29)$ revealed that females needed more trials $(\mathrm{M}=$ 496.66, $\mathrm{SEM}=53.17)$ than males $(\mathrm{M}=401.22, \mathrm{SEM}=$ 


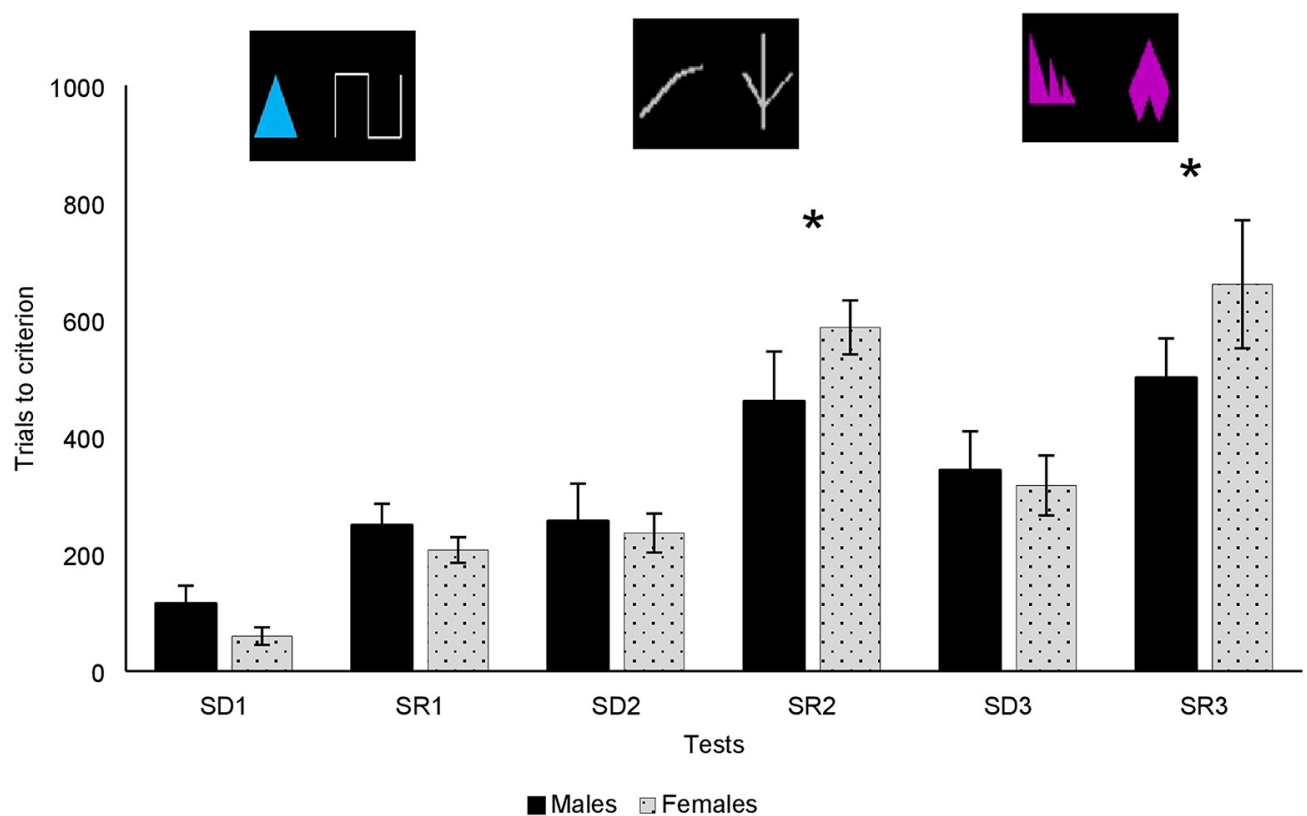

Figure 3. Mean trials to criterion \pm SEM on the SR learning task in males and females; *significantly different at $p<0.05$ (two tailed $t$ test); examples of stimuli shown above.

53.17) to reach criterion on the SRs, but not on the SDs (males: $m=235.16$, SEM $=31.46$, females: $m=$ 213.33, SEM $=31.46$; Fig. 3). A marginal sex $\times$ test type $\times$ pair number $\left(F_{(1.26,23.88)}=3.00, p=0.088\right.$, partial $\eta^{2}=0.14$ ) suggested that females were especially impaired for the more complex pairs, pair 2 and pair 3. RI was significantly greater in females than in males $\left(t_{(20)}=-3.44, p<0.01\right)$, reflecting poorer performance of the females in the reversals, relative to the pre-reversal discriminations.

\section{Errors to criterion}

A significant effect of test type $\left(F_{(1,20)}=120.80, p<\right.$ 0.001 , partial $\eta^{2}=0.86$ ) indicates that animals made significantly more errors during SR trials than during SD trials. A marginal sex $\times$ test type effect $\left(F_{(1,20)}=4.02, p=\right.$ 0.059 , partial $\eta^{2}=0.17$ ) indicates that effect of test type was larger in females than in males. A follow-up ANOVA was performed examining only the more complex pairs 2 and 3 , on which females needed more trials to reach criterion. When pair 1 was removed from the analysis, a

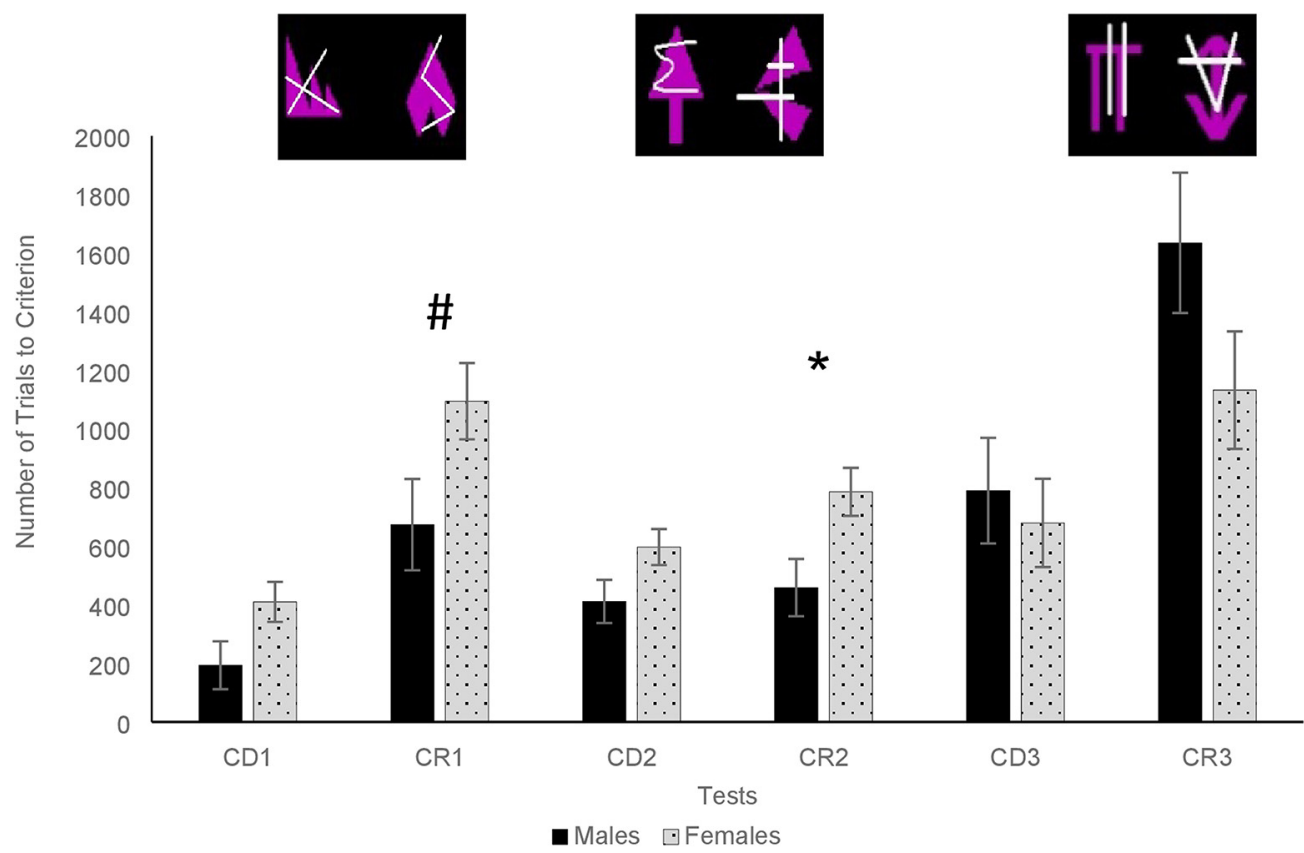

Figure 4. Mean trials to criterion \pm SEM on the ID/ED in males and females; *significantly different at $p<0.05$ (two tailed $t$ test; \# indicates marginal significance, $p=0.057$ ); examples of stimuli shown above. 

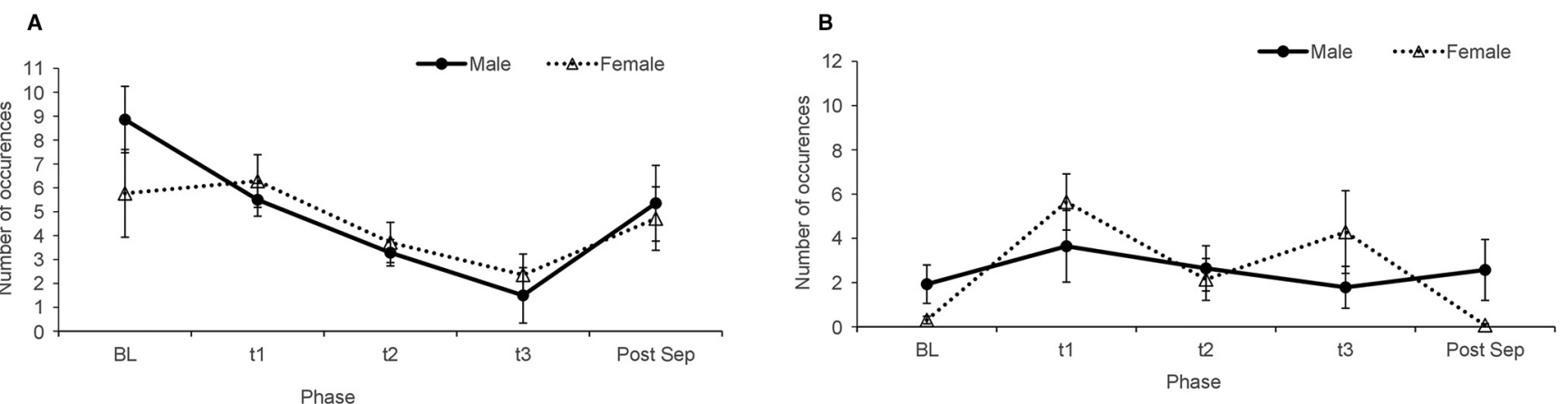

Figure 5. Behaviors before, during, and after separation (means \pm SEM). A, Calm locomotion. $\boldsymbol{B}$, Agitated locomotion.

significant sex $\times$ test type interaction was found $\left(F_{(1,20)}=\right.$ 6.14, $p=0.02$, partial $\eta^{2}=0.24$ ) again indicating that females were more affected by the SR trials in terms of errors than males.

\section{Omissions and RTs}

Monkeys omitted more trials during SRs $(\mathrm{m}=366.02$, $\mathrm{SE}=64.59)$ than during SDs $(m=154.39$, SEM $=25.17)$, as indicated by a significant main effect of test type $\left(F_{(1,19)}\right.$ $=5.87, p=0.03$, partial $\left.\eta^{2}=0.24\right)$. There was also a significant effect of test number $\left(F_{(2,38)}=3.19, p=0.05\right.$, partial $\left.\eta^{2}=0.14\right)$, indicating that monkeys omitted more trials for pair $3(\mathrm{~m}=463.91$, SEM $=50.01)$ and $2(\mathrm{~m}=$ 386.48, SEM $=36.88)$ than pair $1(\mathrm{~m}=159.39$, SEM $=$ 15.48). Importantly, Sex did not affect the omissions $\left(F_{(1,19)}=0.48, p=0.50\right.$, partial $\left.\eta^{2}=0.02\right)$ and there were no significant sex $\times$ test type $\left(F_{(1,19)}=0.01, p=0.91\right.$, partial $\left.\eta^{2}=0.001\right)$ or sex $\times$ test number $\left(F_{(1,38)}=0.007\right.$, $p=0.99$, partial $\eta^{2}<0.001$ ) interactions.

In terms of RT, there were no significant effects of sex $\left(F_{(1,20)}=0.02, p=0.89\right.$, partial $\left.\eta^{2}=0.001\right)$, sex $\times$ test number $\left(F_{(1,20)}=0.03, p=0.972\right.$, partial $\left.\eta^{2}=0.001\right)$, sex $\times$ test type $\left(F_{(1,20)}=0.13, p=0.72\right.$, partial $\left.\eta^{2}=0.006\right)$, or sex $\times$ test number $\times$ test type $\left(F_{(1,20)}=0.4, p=0.67\right.$, partial $\left.\eta^{2}=0.02\right)$.

ID/ED

Seventeen out of the 22 original marmosets completed the ID/ED (10 females, mean age $=5.10$ years, $S D=0.71$;
7 males, mean age $=4.97$ years, $S D=0.32$, means for TTC, sessions, omissions, errors, and response latencies for each sex; Table 2). A significant test type $\times$ pair number interaction $\left(F_{(2,28)}=8.11, p=0.002\right.$, partial $\eta^{2}=$ 0.37 ) indicated that animals needed significantly more trials for CRs on pair 1 and pair 3. A significant interaction between sex and pair number $\left(F_{(2,28)}=3.84, p=0.03\right.$, partial $\eta^{2}=0.22$ ) revealed that females needed more trials to reach criterion than males on pair 1 (females: $m=$ 752.32, SEM = 88.81; males: $m=433.4$, SEM = 106.2; $t_{(15)}=2.37, p=0.03$ ) and pair 2 (females: $m=691.20$, SEM $=53.07$; males: $m=434.93$, SEM $=63.45, t_{(15)}=$ 2.49, $p=0.03$ ) but not on pair 3 (females: $m=906.04$, SEM $=161.32$; males: $m=1212.46$, SEM $=192.90, t_{(15)}$ $=0.94, p=0.36)$. Finally, a marginal sex $\times$ test type $\times$ pair number $\left(F_{(2,28)}=2.58, p=0.093\right.$, partial $\left.\eta^{2}=0.16\right)$ suggested that females were particularly impaired on CR2 (ID reversal; females: $\mathrm{m}=785.33, \mathrm{SEM}=81.90$; males: $\mathrm{m}$ $=458.52$, SEM $=97.93, p=0.02$; Fig. 4), and tended to perform more poorly than males on CR1 (compound reversal; females: $m=1094.87, \mathrm{SEM}=130.38$; males: $m=$ 673.33, SEM $=155.91, p=0.057)$.

\section{Errors to criterion}

There was a significant effect of test type $\left(F_{(1,14)}=\right.$ 64.37, $p<0.001$, partial $\eta^{2}=0.82$ ) with animals making more errors during the CRs than the CDs. There was also a significant effect of pair number $\left(F_{(2,28)}=21.17, p<\right.$

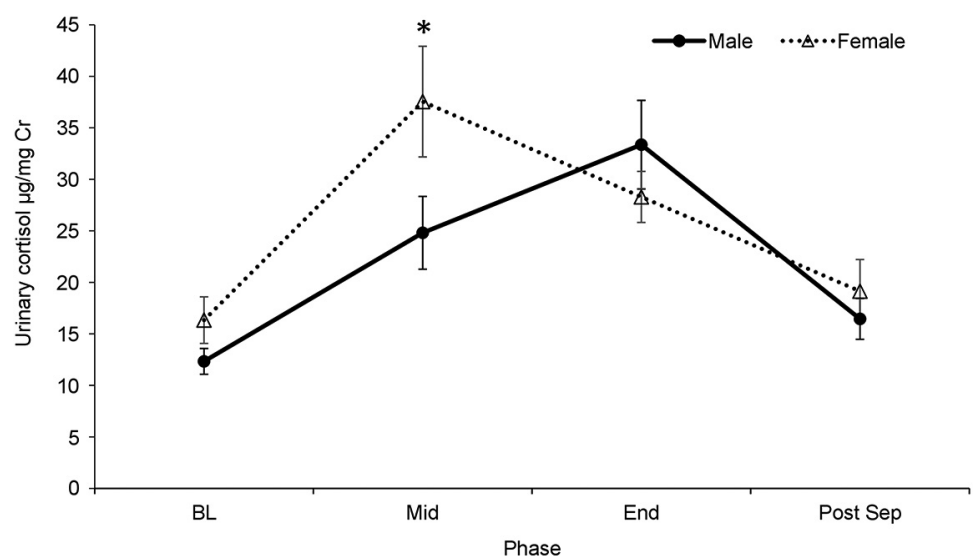

Figure 6. Urinary cortisol (mean \pm SEM) before, during, and the morning following separation in males and females; $*$ significantly different at $p<0.05$ (two tailed $t$ test). 


\section{Female $(n=9)$}

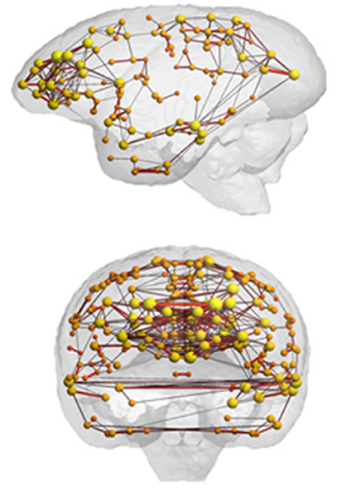

Female brain graph

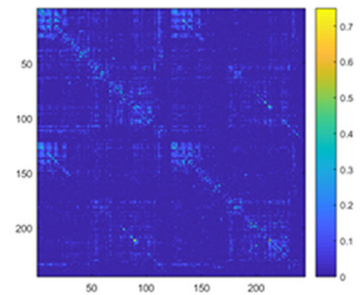

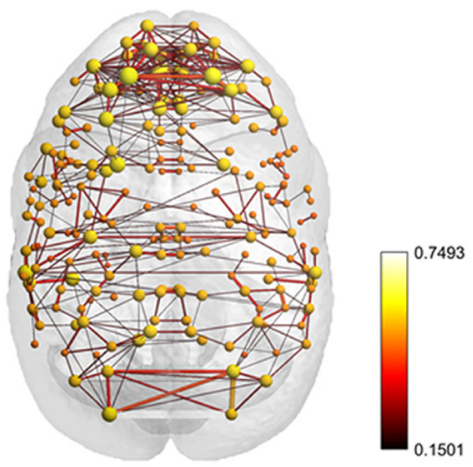
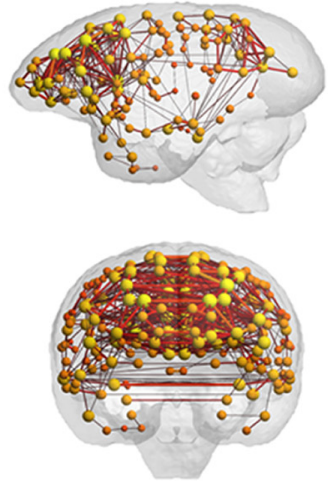

Male brain graph

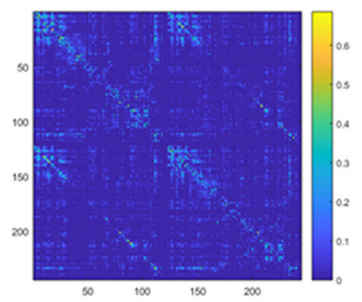

Figure 7. 3D functional network maps of the marmoset monkey brain display increased clustering in the males relative to females. Shown are sagittal, coronal, and axial views of nodes (spheres) and edges (connecting lines) overlaid onto a 3D atlas map shell. Maps are thresholded at $z>0.2$ and maps represent the top $10 \%$ of connections (density $k=0.10$ ). The matrices below are mean functional connectivity matrices for male and female brains and their randomly rewired versions with the same density and edge weights and randomly assigned connections.
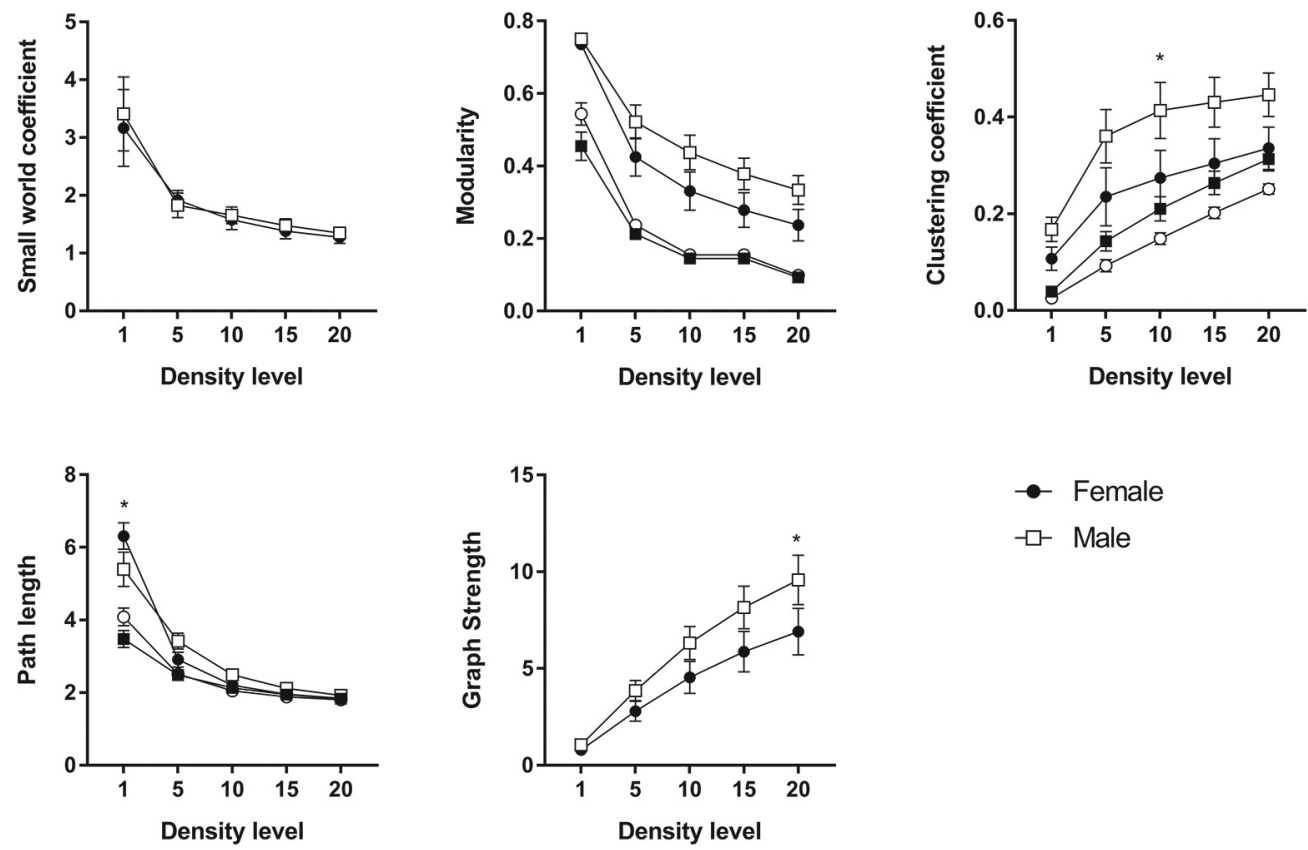
$\rightarrow$ Female
$-\square-$ Male

Figure 8. Functional network metrics indicate that males have a greater clustering coefficient than females; *significantly different at $p<0.05$ (two tailed $t$ test). Filled circles represent female data, and empty squares represent males. Empty circles and filled squares represent the same metrics calculated for random networks with the same density and edge weights. 


\section{a. Females}
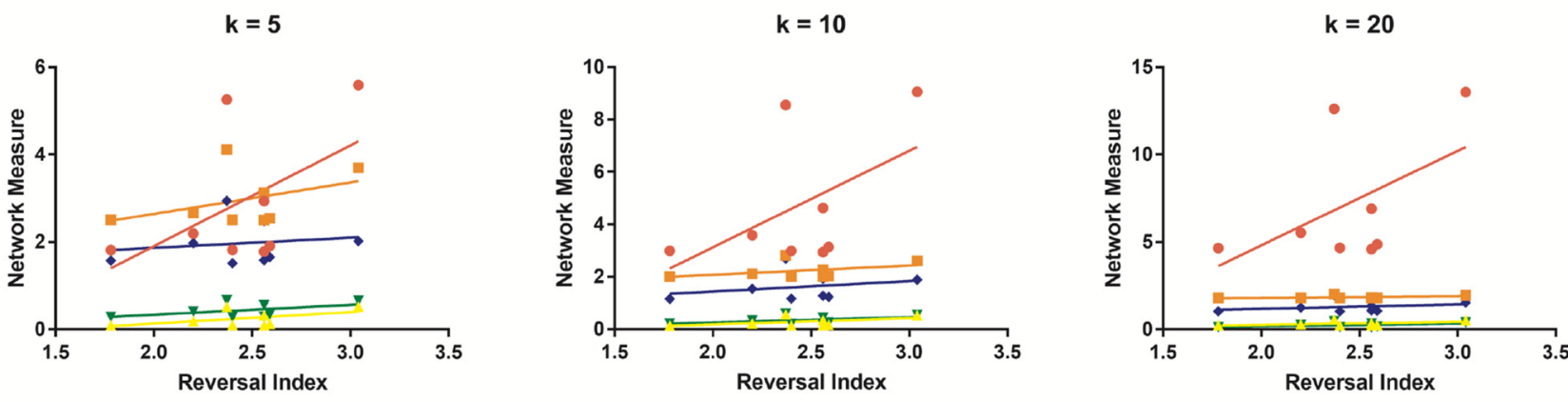

\section{b. Males}
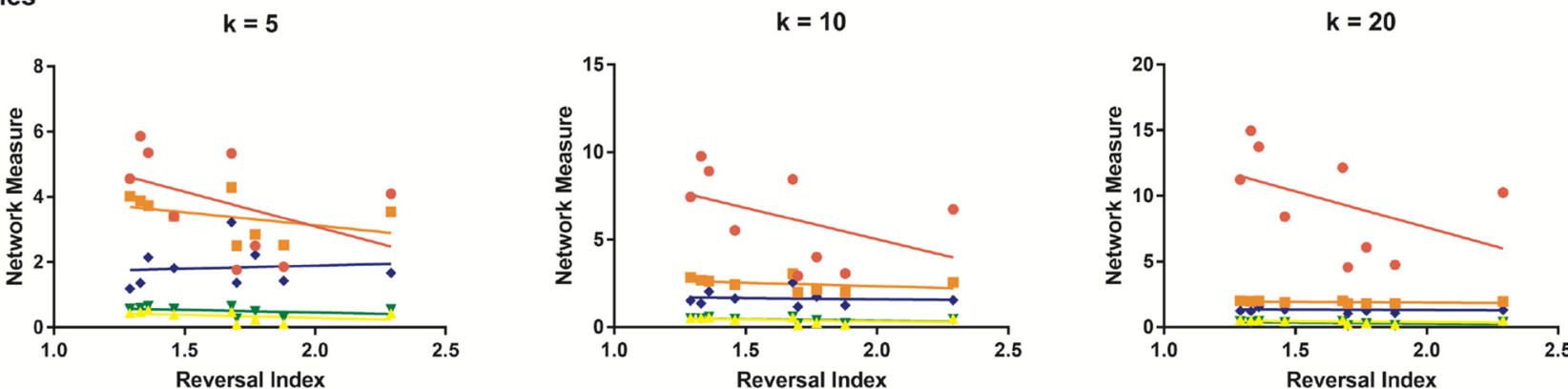

- Strength
-- Path length
- Clustering coefficient
$\rightarrow$ Modularity
$\rightarrow$ Small Worldness

Figure 9. Functional network strength is positively correlated with cognitive performance in females and negatively correlated in males. $\boldsymbol{A}$, Linear regression between $\mathrm{RI}$ and several network measures (strength, path length, clustering, modularity, small worldness) indicates a positive correlation between only node strength and RI. B. Similar to females, only node strength covaries with $\mathrm{RI}$ values. However, in males, this is observed as a negative correlation; $\mathrm{k}$ values represent different connectivity density thresholds.

0.001 , partial $\left.\eta^{2}=0.60\right)$, with animals making more errors on pair 3 (ED shift/reversal) than on pair 1 (compound discrimination/reversal) or pair 2 (ID shift/reversal). The effect of $\operatorname{sex}\left(F_{(1,14)}=1.91, p=0.12\right.$, partial $\left.\eta^{2}=0.16\right)$, sex $\times$ test type $\left(F_{(1,14)}=0.78, p=0.39\right.$, partial $\left.\eta^{2}=0.05\right)$, sex $\times$ pair number $\left(F_{(2,28)}=2.35, p=0.11\right.$, partial $\eta^{2}=$ $0.14)$, or sex $\times$ pair number $\times$ test type interactions $\left(F_{(2,28)}\right.$ $=0.40, p=0.68$, partial $\eta^{2}=0.03$ ) were not significant.

\section{Omissions and RTs}

There was a significant main effect of test type $\left(F_{(1,14)}=\right.$ 9.45, $p=0.008$, partial $\eta^{2}=0.40$ ) indicating monkeys omitted more trials on CRs $(\mathrm{m}=356.51$, SEM $=68.25)$ than on CDs $(m=228.33$, SEM $=52.76)$. There was also a significant effect of pair number $\left(F_{(2,28)}=6.47, p=\right.$ 0.005 partial $\eta^{2}=0.32$ ) with animals omitting more trials on pair $3(\mathrm{~m}=357.29$, SEM $=68.37)$ than on pair $1(\mathrm{~m}=$ 229.99, SEM $=50.73$ ). Sex had no effect on omissions $\left(F_{(1,14)}=0.14, p=0.72\right.$, partial $\left.\eta^{2}=0.01\right)$, and there were no significant sex $\times$ test type $\left(F_{(1,14)}=2.77, p=0.12\right.$, partial $\left.\eta^{2}=0.17\right)$ or sex $\times$ pair number $\left(F_{(1,14)}=2.23, p=\right.$ 0.13 , partial $\eta^{2}=0.14$ ) interactions.
In terms of RT, there were no significant effects of sex $\left(F_{(1,14)}=0.012, p=0.91\right.$, partial $\left.\eta^{2}=0.001\right)$ and no significant sex $\times$ pair number interactions $\left(F_{(2,28)}=2.05\right.$, $p=0.15$, partial $\eta^{2}=0.13$ ). Unlike RT for the reversals, a marginally significant sex $\times$ test type interaction was found $\left(F_{(1,14)}=3.33, p=0.09\right.$, partial $\left.\eta^{2}=0.19\right)$. Follow-up comparisons indicated that males had significantly longer RT on initial discriminations $(m=2458.72$ $\mathrm{ms}$, SEM $=186.22 \mathrm{~ms})$ than on reversal trials $(\mathrm{m}=$ $2154.47 \mathrm{~ms}$, SEM $=174.95 \mathrm{~ms}, p=0.02$ ). Importantly, males and females did not significantly differ on RT on the initial discriminations $(p=0.65)$ or the reversal trials $(p=$ 0.49 ). Finally, there were no significant sex $\times$ pair number $\times$ test type interactions $\left(F_{(2,28)}=0.65, p=0.53\right.$, partial $\eta^{2}$ $=0.04)$.

\section{Social separation task}

\section{Behavior}

Twenty-eight monkeys ( 14 females, mean age $=4.94$ years, $S D=0.68 ; 14$ males, mean age $=4.73$ years, SD $=0.52$ ) completed the social separation task. For agitated locomotion, there was a marginally significant sex $\times$ test 

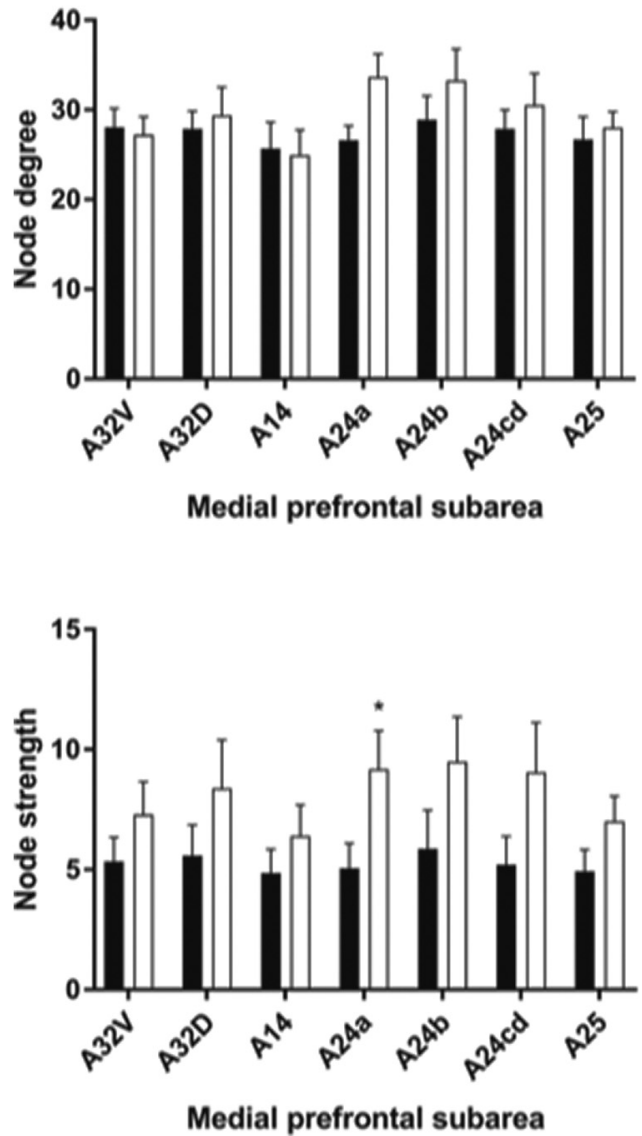

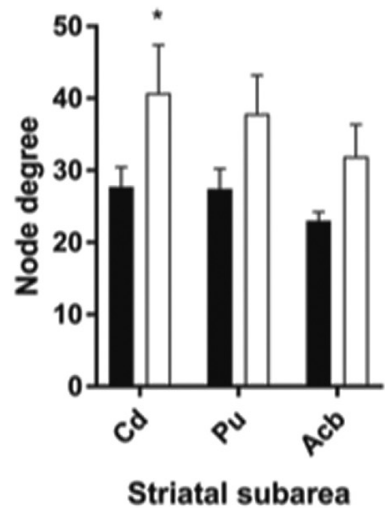

Striatal subarea

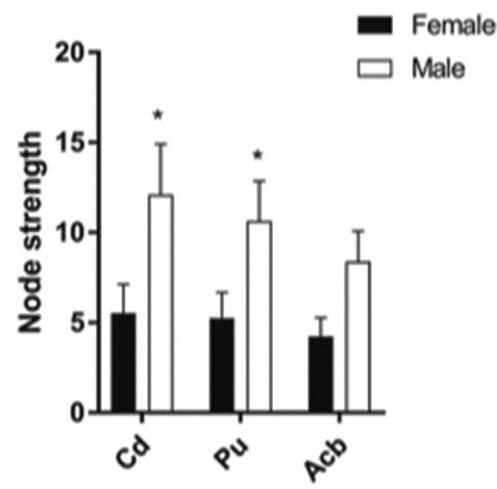

Striatal subarea

Figure 10. Medial prefrontal cortex (area 24) and caudate nucleus exhibit greater node strength in male marmosets compared to females; *significantly different at $p<0.05$ (two tailed $t$ test).

phase interaction $\left(F_{(2,28)}=3.04, p=0.06\right.$, partial $\eta^{2}=$ $0.18)$. Follow-up $t$ tests showed that females exhibited greater agitated locomotion during Sep than $\mathrm{BL}(p=0.02)$ or Post-Sep $(p=0.06)$. Males' agitated locomotor behavior was unaffected by the social separation (all $p s>0.05$; Fig. $5 B$ ). Sex did not affect calm locomotion, but there was an effect of test phase $\left(F_{(2,28)}=4.86, p=0.015\right.$, partial $\left.\eta^{2}=0.26\right)$, with a decrease in calm locomotion from BL to Sep $(p=0.022)$ in both sexes (Fig. $5 A)$.

\section{Cortisol levels}

Test phase had a significant effect on urinary cortisol levels $\left(F_{(3,30)}=9.63, p<0.001\right.$, partial $\left.\eta^{2}=0.49\right)$, with an increase in cortisol from $B L$ to $t 2(p=0.003)$ and from $B L$ to $\mathrm{t} 3(p=0.006)$ and a return to BL levels of cortisol by the Post-Sep phase ( $p=0.06$; Fig. 6$)$. To further investigate the relationship between sex and test phase, paired samples $t$ tests were used to compare $\mathrm{BL}$ to $\mathrm{t} 2, \mathrm{t} 3$, and Post-Sep cortisol levels in females and males. A Bonferroni correction was used to correct for multiple comparisons. For females, cortisol levels significantly increased from BL to t2 $\left(t_{(5)}=3.81, p=0.013\right)$ and $\mathrm{t} 3\left(t_{(9)}=3.39, p\right.$ $=0.008)$, but returned to BL levels by the Post-Sep cortisol measurement $\left(t_{(11)}=0.77, p=0.459\right)$. In males, the increase in cortisol was delayed, with levels being similar to $\mathrm{BL}$ at $\mathrm{t} 2\left(t_{(6)}=2.04, p=0.087\right)$, significantly increased from $\mathrm{BL}$ at $\mathrm{t} 3\left(t_{(13)}=4.77, p<0.001\right)$ and not significantly different from BL at Post-Sep $\left(t_{(13)}=1.82, p\right.$ $=0.092$ ).

\section{Stress and cognitive interactions}

$\mathrm{RI}$ was not significantly correlated with change in cortisol from BL to t2 $\left(r_{(8)}=-0.004, p=0.99\right)$, or change in cortisol from BL to t3 $\left(r_{(18)}=-0.12, p=0.61\right)$. RI was also not significantly correlated with change in agitated locomotion from BL to t1 $\left(r_{(19)}=0.22, p=0.35\right)$, from $\mathrm{BL}$ to $\mathrm{t} 2$ $\left(r_{(19)}=0.12, p=0.60\right)$, or from BL to t3 $\left(r_{(19)}=0.25, p=\right.$ $0.27)$. Interestingly, independent of sex, Rl was significantly correlated with basal cortisol $\left(r_{(20)}=0.47, p=\right.$ 0.026).

\section{Hill and valley task}

Twenty-one monkeys ( 11 females and 10 males) completed the hill and valley task. The strength of the lateral bias $(\mathrm{HI})$ did not differ between left and right handed individuals (independent $t$ test, $t_{(13)}=-1.41, p=0.18$ ). We examined the effects of Sex and Hand Use on the latencies to complete the tests as well as test scores, with $\mathrm{HI}$ as a covariate. For the latencies, there were no significant effects of hand use $\left(F_{(1,18)}=0.19, p=0.67\right.$, partial $\left.\eta^{2}=0.01\right)$, sex $\left(F_{(1,18)}=0.12, p=0.73\right.$, partial $\eta^{2}=$ $0.007)$, and no significant sex $\times$ hand use interaction $\left(F_{(1,18)}=0.218, p=0.64\right.$, partial $\left.\eta^{2}=0.012\right)$. For the score, there were no significant effects of hand use $\left(F_{(1,18)}\right.$ 

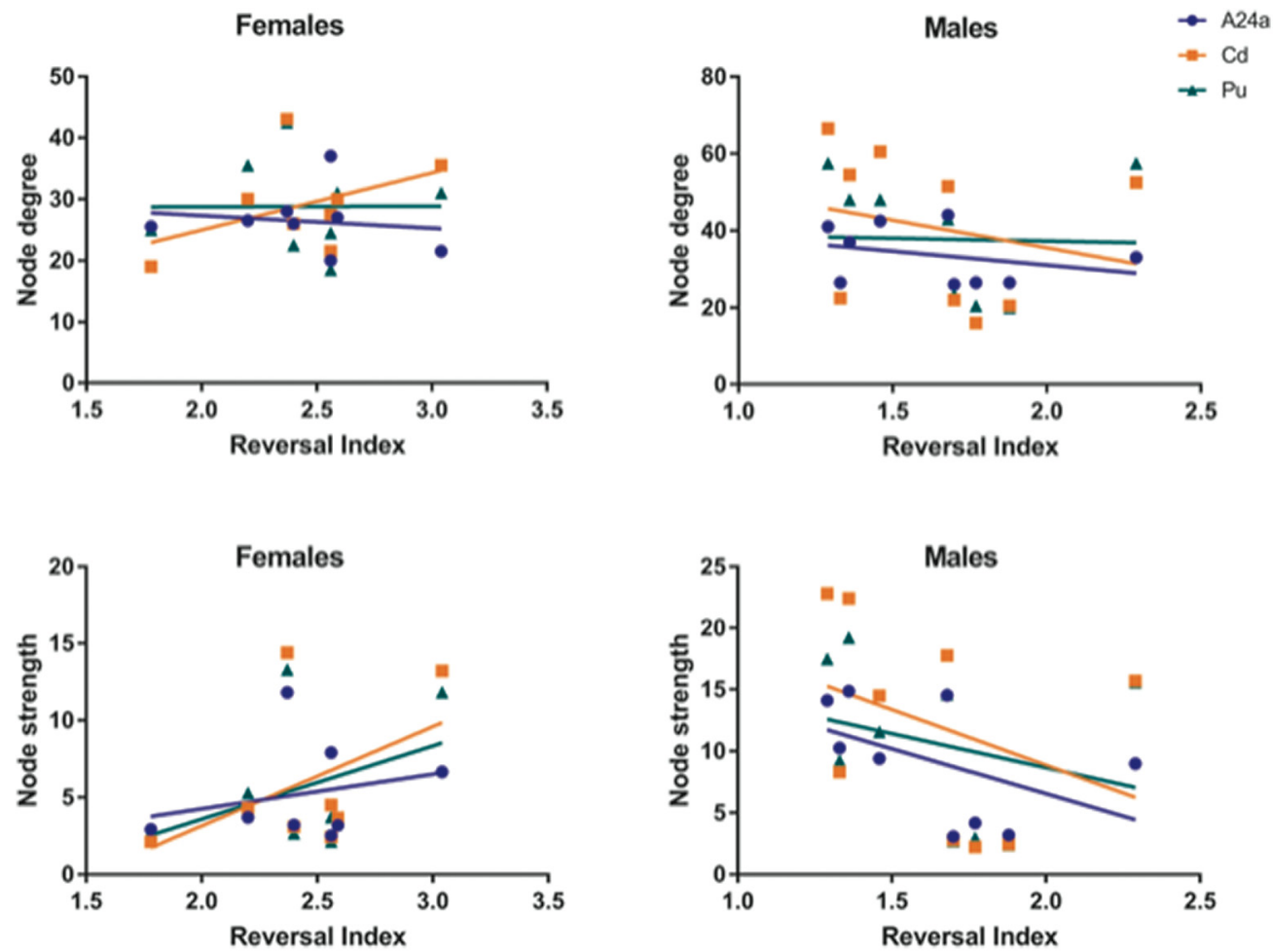

Figure 11. Functional network strength (and not node degree) in medial prefrontal cortex and caudate nucleus is positively correlated with cognitive reversal learning in females and negatively correlated in males.

$=0.31, p=0.59$, partial $\left.\eta^{2}=0.02\right), \operatorname{sex}\left(F_{(1,18)}=0.45, p\right.$ $=0.51$, partial $\eta^{2}=0.02$ ), and no significant sex $\times$ hand use interaction $\left(F_{(1,18)}=2.79, p=0.11\right.$, partial $\left.\eta^{2}=0.31\right)$.

\section{rsFC}

Animals with cognitive data (nine female, mean age $=$ 6.12 years, $S D=0.73$; nine male, mean age $=5.88, S D=$ 0.57 years) were imaged, all within three months of cognitive testing. 3D functional network maps of the marmoset monkey brain revealed higher clustering in the males relative to females (Fig. 7), and functional network metrics indicated a greater clustering coefficient in males than females ( $p<0.05$; Fig. 8). Network node strength was positively correlated with the RI in females and negatively correlated in males, with a greater Rls reflecting poorer reversal performance. Linear regression between $\mathrm{RI}$ and several network measures (strength, path length, clustering, modularity, small worldness) indicated a positive correlation between node strength and $\mathrm{Rl}$ in females, suggesting that greater node strength is associated with worse reversal performance in females. Similar to females, only node strength covaried with $\mathrm{Rl}$ values in males, however, this correlation was negative (Fig. 9), indicating that greater node strength in males is associated with better reversal performance. Node strength in the medial prefrontal cortex (area 24) and the caudate nucleus was greater in male marmosets $(p<0.05$; Fig. 10). Functional network strength (but not node degree) in the medial prefrontal cortex and the caudate nucleus was positively correlated with $\mathrm{Rl}$ in females and negatively correlated in males (Fig. 11). Seed based functional connectivity values in multiple medial prefrontal cortex sub- divisions $(p<0.05$; Figs. 12, 14) and the caudate, putamen, and NAc ( $p<0.05$; Figs. 13,14$)$ indicate that males have greater functional connectivity with these regions than females.

\section{Discussion}

We tested female and male marmosets on two executive function tasks: SR learning, a measure of cognitive flexibility, and the ID/ED, a measure of attentional set shifting. In SR learning, females performed more poorly than males in acquiring the reversals, especially for pair 2 and pair 3 , which used stimuli (two shapes or two lines) that were more difficult to differentiate than those of pair 1 (shape vs line), as evidenced by an increase in both the number of trials necessary to reach learning criteria and the number of errors. Consistent with these findings, females also needed more trials to reach learning criterion on the reversal portions of the ID/ED, particularly on pair 1 and pair 2 reversals which required them to perform reversals without a change in attentional set. However, females performed similar to males on the ID or ED shifts. These findings point to a deficit of females specific to reversal learning, independent of a deficit in attentional set shifting. We ruled out motivation as a main contributor of this sex difference, as there was no sex difference in the number of trials the animals omitted or RT. Additionally, monkeys' motor skills in the hill and valley were similar between males and females, thus it is unlikely that sex differences in cognitive performance were due to differences in motor ability.

We found a significant female deficit on reversal learning. This female deficit was specific to reversal acquisition 


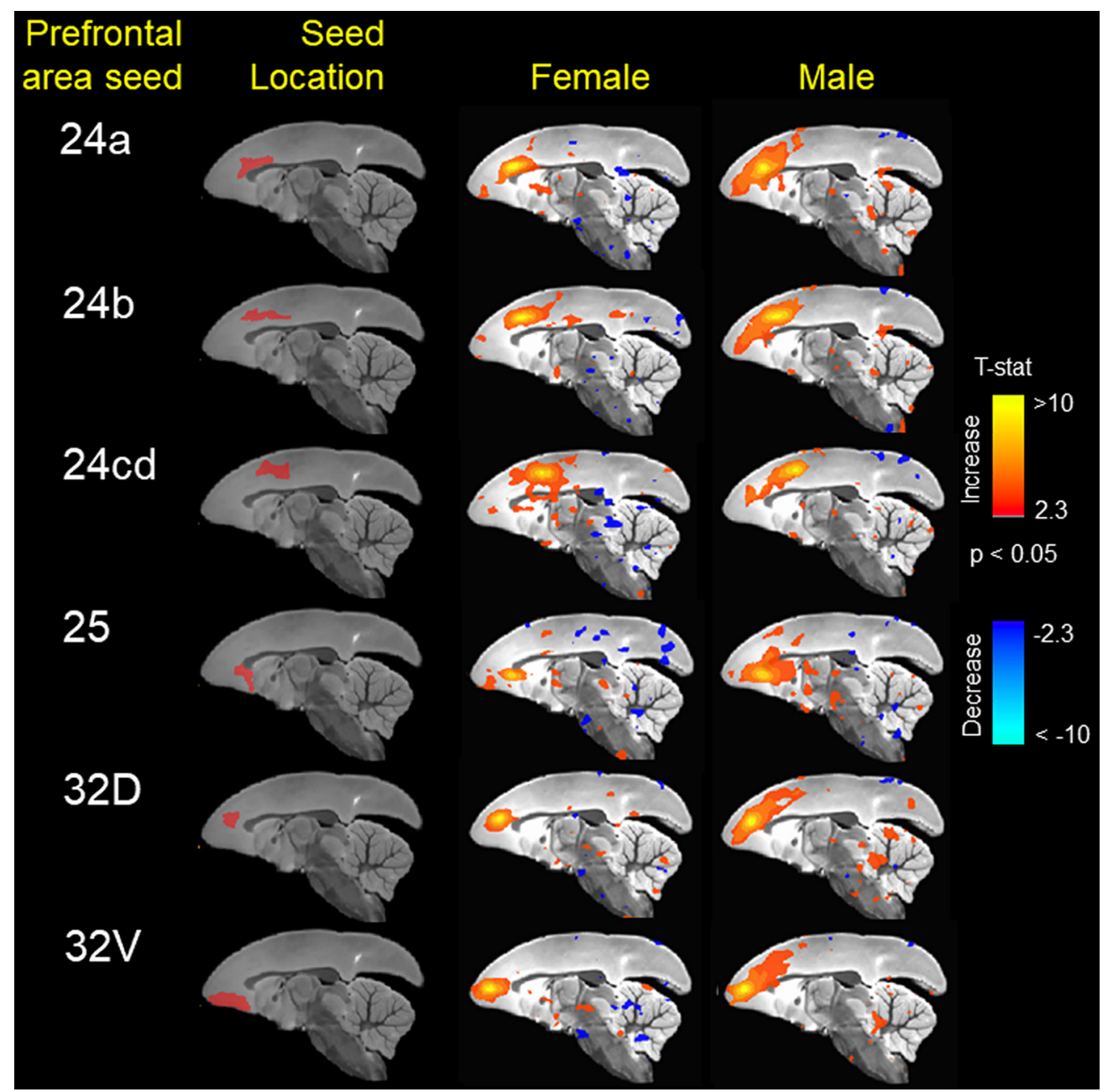

Figure 12. Seed based functional connectivity in various medial prefrontal cortex subdivisions indicates that males have greater functional connectivity with these regions than females. Maps represent mean functional connectivity across all animals within each group, thresholded by statistical $t$ values $(t>2.3, p<0.05$ ).

and to the pairs that were most difficult to discriminate because the stimuli shared similar features (e.g., two lines of the same color). This finding is in agreement with human literature, which finds a male advantage in reversal learning in both children (Overman, 2004) and adults (Evans and Hampson, 2015). Interestingly, no sex difference was found in the first pair of stimuli, which involved discriminating between two stimuli with clearly different features, a shape and a line of different colors. This suggests that sex differences in reversal learning are sensitive to perceptual complexity, with the male advantage emerging only when the reinforcement contingencies involve discriminating among stimuli sharing similar features.

In the ID/ED task, marmosets needed more trials to acquire the ED than the ID. This finding is in agreement with previous studies, which have asserted that a shift within the same attentional set (ID shift) is acquired more rapidly than a shift to a new attentional set (ED shift; Owen et al., 1991; Dias et al., 1996). However, no sex difference was found in the ability to perform the ID or ED.

There is ample evidence that reversal learning and attentional set shifting are controlled by anatomically dis- crete brain regions. Two brain regions seem to be critical to reversal learning: the OFC and the striatum (for review, see Izquierdo et al., 2017). Functional imaging studies in humans have shown increased activation in the OFC during reversal learning paradigms (Nagahama et al., 2001; Cools et al., 2002; Ghahremani et al., 2010) and studies in NHPs have shown that lesions to the OFC cause disruptions in reversal, but not in the initial stimulus-reward associations (Izquierdo, 2004; Machado and Bachevalier, 2007). Dias et al. (1996) compared the performance of marmosets with OFC lesions, animals with lesions to the dorsolateral PFC (DLPFC), and shamlesioned animals. Marmosets with OFC lesions showed impairments in reversal learning, but ED set shifting remained intact, while animals with DLPFC lesions showed opposite deficits. A similar pattern has been shown in rodent research, with lesions to the OFC impairing reversal learning but leaving attentional set shifting intact (McAlonan and Brown, 2003). In addition to the OFC, the striatum, which receives strong projections from the OFC, significantly contributes to reversal learning. Lesions to the medial striatum (Clarke et al., 2008) or dopaminergic 


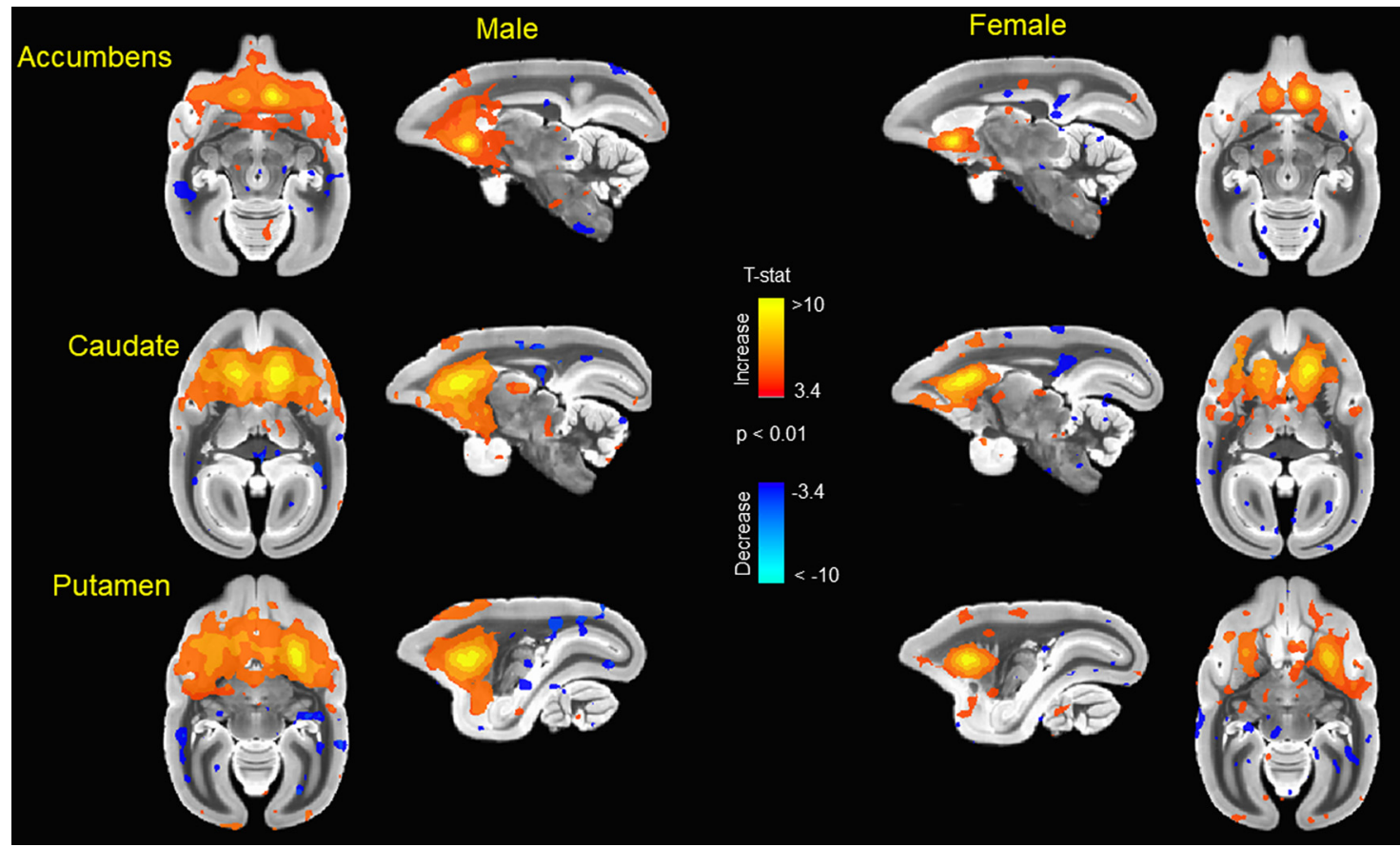

Figure 13. Seed based functional connectivity in caudate nucleus, putamen, and nucleus accumbens indicates that males have greater functional connectivity with these regions than females. Maps represent mean functional connectivity across all animals within each group, thresholded by statistical $t$ values $(t>2.3, p<0.05)$

depletion within the caudate (Clarke et al., 2011) cause impairments in reversal learning in the marmoset. Furthermore, a recent study found that infusion of the GABA agonist muscimol into the putamen led to impairments in reversal acquisition, while leaving SD unchanged (Jackson et al., 2019).

Based on these findings, it is likely that the observed sex difference in reversal acquisition reflects differences at the OFC/striatum level. The OFC has been implicated in the encoding of the associative value of a reward and is critical for updating this value for future decisions (Haber and Knutson, 2010). In contrast, the dorsal striatum mediates the acquisition and expression of habitual behavior, when the stimulus-response associations become automatized and less sensitive to the outcome (FernandezRuiz et al., 2001; Miyachi et al., 2002; Graybiel and
Grafton, 2015). This region of the striatum is also highly sensitive to estrogens (Di Paolo et al., 1985; Korol et al., 2004; Shams et al., 2016). In a prior study, we reported that estradiol (E2) replacement impairs reversal acquisition in ovariectomized female marmosets (Lacreuse et al., 2014), consistent with a detrimental effect of E2 on the dopaminergic striatal system. A recent study demonstrated that female rats engage in habitual behavior more rapidly than male rats during operant responding (Schoenberg et al., 2019). Based on these findings and the literature reviewed above, one interpretation of our results is that female marmosets may engage in habitual behavior earlier and/or to a greater extent than male marmosets while learning stimulus-response contingencies, impairing their ability to flexibly respond to new contingencies during reversal. The female impairment is most likely driven
Seed: A24a

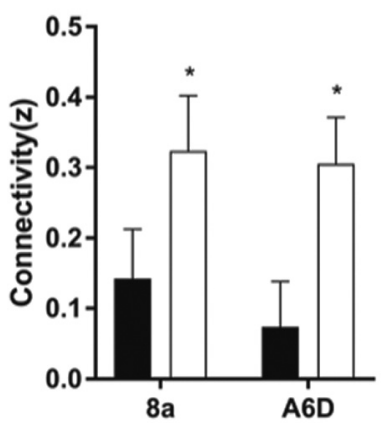

Seed: Caudate

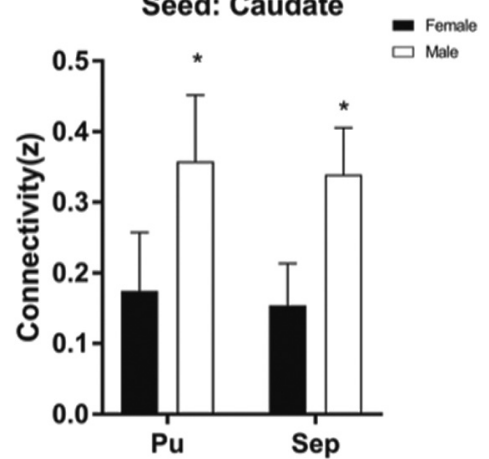

Figure 14. Greater functional connectivity in frontal cortical and striatal circuits of male marmosets compared to females. Seed regions are indicated above the plots; *significantly different at $p<0.05$ (two tailed $t$ test). Area 8 a is located in the dorsolateral prefrontal cortex and A6D in the premotor cortex. Pu, putamen; Sep, septum. 
by effects of estrogens on the striatal dopaminergic system. Accordingly, one would expect reversal learning performance to vary with cycling endogenous E2 levels in female marmosets, as found for other striatal-dependent tasks in rodents (Becker et al., 1987). The specific mechanisms underlying these effects will have to be determined in future studies.

We examined whether stress reactivity to temporary social separation differed between males and females. While both sexes responded to the social stressor with decreased calm locomotion and an increase in cortisol, females, but not males, exhibited a significant increase in agitated locomotion during the stressor compared to baseline. In addition, the increase in cortisol levels occurred earlier in the separation for females than males. The significance of these findings is not entirely clear, but could reflect a delayed response to social stress in males. Basal cortisol was positively correlated with RI, indicating that increased basal cortisol was associated with poorer reversal performance for both sexes. This finding, consistent with human data (Kalmijn et al., 1998; Lee et al., 2007; Comijs et al., 2010), suggests that basal cortisol could be a marker for future age-related cognitive decline (Greendale et al., 2000; Beluche et al., 2010; Ennis et al., 2017; Pietrzak et al., 2017). Our ongoing longitudinal studies will determine the validity of this hypothesis.

Marmosets exhibit diurnal fluctuations in cortisol, with peak levels in the morning ( $9-10$ A.M.) and decreasing throughout the day (Smith and French, 1997; Cross et al., 2004). In our animals, peak cortisol for females occurred at between 12 and 2 P.M. and between 2 and 4 P.M. for males, indicating that the pattern of cortisol increase was likely due to social separation paradigm and not attributable to normal diurnal cortisol fluctuations.

Important novel findings from the neuroimaging work indicate that (1) rsFC also revealed significant sex differences in connectivity patterns and activity strength and (2) rsFC patterns were differentially related to cognitive flexibility in males versus females. Specifically, male brains exhibited higher clustering of functional networks than females, had greater node strength in the medial PFC and the caudate nucleus, and greater functional connectivity than females in frontal cortical and striatal circuits. Interestingly, network strength was associated with better reversal performance in males, but worse reversal performance in females.

Prefrontal cortical circuits and striatal circuits have been identified as regions critical for reversal learning in marmosets (Clarke et al., 2005; Rygula et al., 2010; Jackson et al., 2019) with several neurotransmitters, including serotonin (Clarke et al., 2005), dopamine (Clarke et al., 2011), GABA (Jackson et al., 2019), and glutamate + glutamine Glx (Lacreuse et al., 2018) influencing cognitive performance. All these neurotransmitters are influenced by sex hormones (Barth et al., 2015) and at least one study reported a sex-dependent effect of Glx on reversal learning performance in marmosets (Lacreuse et al., 2018). In addition, these neurotransmitters (Lurie et al., 2018) as well as sex hormones (Arélin et al., 2015) also influence the architecture of functional connectivity net- works. Human studies have suggested that sex differences in cognition are represented at the neural level by sex differences in the brain connectome (Gong et al., 2011; Ingalhalikar et al., 2014; Satterthwaite et al., 2015; Tunç et al., 2016; Ritchie et al., 2018). However, some data have been inconsistent (Satterthwaite et al., 2015 vs Tunç et al., 2016) and criticized for over-interpretation (Joel and Tarrasch, 2014). Animal studies, which minimize sociocultural influences on network activity and cognitive performance, may help clarify these relationships. It is important to note that the relationship between reversal learning and rsFC is correlational, and as such, causation cannot be asserted with our current data. However, as resting state network activation has been shown to reflect task-evoked activity in multiple studies (Mennes et al., 2010; Kannurpatti et al., 2012; Zou et al., 2013), it is likely that the male pattern of connectivity in our study represents a pattern that is more advantageous for reversal learning. Future studies should determine the potential role of sex hormones and neurotransmitters in shaping the functional connectome in males and females.

In summary, we found that female marmosets had poorer reversal learning relative to males. rsFC analyses revealed substantial sex differences in cognitive networks, with differences in both overall neural network metrics and specific regions, including the prefrontal cortex, caudate, putamen, and nucleus accumbens. Sexdependent correlations between reversal learning and neural connectivity measures suggest that to sexdependent patterns of resting brain networks may contribute to the sex difference in reversal learning. Although our data are correlational and cannot determine causal effects, they are consistent with human resting state data in supporting the idea that sex differences in cognitive performance have identifiable intrinsic neural correlates (de Lacy et al., 2019). Because of its relatively short lifespan, the marmoset should be particularly helpful in furthering our understanding of the dynamics of sex differences in cognition and associated brain networks across the lifespan.

\section{References}

Arélin K, Mueller K, Barth C, Rekkas PV, Kratzsch J, Burmann I, Villringer A, Sacher J (2015) Progesterone mediates brain functional connectivity changes during the menstrual cycle-a pilot resting state MRI study. Front Neurosci 9:44.

Badihi I, Morris K, Buchanan-Smith HM (2008) The effects of increased space, complexity, and choice, together with their loss, on the behavior of a family group of Callithrix jacchus: a case study. 47:1962-1987.

Barth C, Villringer A, Sacher J (2015) Sex hormones affect neurotransmitters and shape the adult female brain during hormonal transition periods. Front Neurosci 9:37.

Becker JB, Snyder PJ, Miller MM, Westgate SA, Jenuwine MJ (1987) The influence of estrous cycle and intrastriatal estradiol on sensorimotor performance in the female rat. Pharmacol Biochem Behav 27:53-59.

Belcher AM, Yen CC, Stepp H, Gu H, Lu H, Yang Y, Silva AC, Stein EA (2013) Large-scale brain networks in the awake, truly resting marmoset monkey. J Neurosci 33:16796-16804.

Belcher AM, Yen CC-C, Notardonato L, Ross TJ, Volkow ND, Yang Y, Stein EA, Silva AC, Tomasi D (2016) Functional connectivity 
hubs and networks in the awake marmoset brain. Front Integr Neurosci 10:9.

Beluche I, Carriere I, Ritchie K, Ancelin ML (2010) A prospective study of diurnal cortisol and cognitive function in communitydwelling elderly people. Psychol Med 40:1039-1049.

Bihel E, Pro-Sistiaga P, Letourneur A, Toutain J, Saulnier R, Insausti R, Bernaudin M, Roussel S, Touzani O (2010) Permanent or transient chronic ischemic stroke in the non-human primate: behavioral, neuroimaging, histological, and immunohistochemical investigations. J Cereb Blood Flow Metab 30:273-285.

Boccaletti S, Latora V, Moreno Y, Chavez M, Hwang DU (2006) Complex networks: structure and dynamics. Phys Rep 424:175308.

Chaplin TA, Yu H-H, Soares JGM, Gattass R, Rosa MGP (2013) A conserved pattern of differential expansion of cortical areas in simian primates. J Neurosci 33:15120-15125.

Clarke HF, Walker SC, Crofts HS, Dalley JW, Robbins TW, Roberts AC (2005) Prefrontal serotonin depletion affects reversal learning but not attentional set shifting. J Neurosci 25:532-538.

Clarke HF, Robbins TW, Roberts AC (2008) Lesions of the medial striatum in monkeys produce perseverative impairments during reversal learning similar to those produced by lesions of the orbitofrontal cortex. J Neurosci 28:10972-10982.

Clarke HF, Hill GJ, Robbins TW, Roberts AC (2011) Dopamine, but not serotonin, regulates reversal learning in the marmoset caudate nucleus. J Neurosci 31:4290-4297.

Colon-Perez LM, Goldberger BA, Blum K, Febo M, Pace MC, Bruijnzeel AW, Gold MS, Thompson K, Tran K, Setlow B (2016) The psychoactive designer drug and bath salt constituent MDPV causes widespread disruption of brain functional connectivity. Neuropsychopharmacology 41:2352-2365.

Cools R, Clark L, Owen AM, Robbins TW (2002) Defining the neural mechanisms of probabilistic reversal learning using event-related functional magnetic resonance imaging. J Neurosci 22:45634567.

Comijs HC, Gerritsen L, Penninx BW, Bremmer MA, Deeg DJ, Geerlings $\mathrm{MI}$ (2010) The association between serum cortisol and cognitive decline in older persons. Am J Geriatr Psychiatry 18:42-50.

Cox RW (1996) AFNI: software for analysis and visualization of functional magnetic resonance neuroimages. Comput Biomed Res 29:162-173.

Cross N, Pines MK, Rogers LJ (2004) Saliva sampling to assess cortisol levels in unrestrained common marmosets and the effect of behavioral stress. Am J Primatol 62:107-114.

de Lacy N, McCauley E, Kutz JN, Calhoun VD (2019) Multilevel mapping of sexual dimorphism in intrinsic functional brain networks. Front Neurosci 13:332.

Dias R, Robbins TW, Roberts a. C (1996) Primate analogue of the Wisconsin card sorting test: effects of excitotoxic lesions of the prefrontal cortex in the marmoset. Behav Neurosci 110:872-886.

Di Paolo T, Rouillard C, Bédard P (1985) 17 beta-estradiol at a physiological dose acutely increases dopamine turnover in rat brain. Eur J Pharmacol 117:197-203.

Ennis GE, An Y, Resnick SM, Ferrucci L, O'Brien RJ, Moffat SD (2017) Long-term cortisol measures predict Alzheimer disease risk. Neurology 88:371-378.

Erdös P, Rényi A (1960) Additive properties of random sequences of positive integers. Acta Arith 6:83-110.

Eslamboli A, Baker HF, Ridley RM, Annett LE (2003) Sensorimotor deficits in a unilateral intrastriatal 6-OHDA partial lesion model of Parkinson's disease in marmoset monkeys. Exp Neurol 183:418429.

Evans KL, Hampson E (2015) Sex differences on prefrontallydependent cognitive tasks. Brain Cogn 93:42-53.

Fernandez-Ruiz J, Wang J, Aigner TG, Mishkin M (2001) Visual habit formation in monkeys with neurotoxic lesions of the ventrocaudal neostriatum. Proc Natl Acad Sci USA 98:4196-4201.

Flashman J (2013) A cohort perspective on gender gaps in college attendance and completion. Res High Educ 54:545-570.
French JA, Fite JE, Jensen $\mathrm{H}$, Oparowski K, Rukstalis MR, Fix $\mathrm{H}$, Jones B, Maxwell H, Pacer M, Power ML, Schulkin J (2007) Treatment with $\mathrm{CRH}-1$ antagonist antalarmin reduces behavioral and endocrine responses to social stressors in marmosets (Callithrix kuhlii). Am J of Primatol 69:877-889.

Ghahremani DG, Monterosso J, Jentsch JD, Bilder RM, Poldrack RA (2010) Neural components underlying behavioral flexibility in human reversal learning. Cereb Cortex 20:1843-1852.

Gong G, He Y, Evans AC (2011) Brain connectivity: gender makes a difference. Neuroscientist 17:575-591.

Graybiel AM, Grafton ST (2015) The striatum: where skills and habits meet. Cold Spring Harb Perspect Biol 7:a021691.

Greendale GA, Kritz-Silverstein D, Seeman T, Barrett-Connor E (2000) Higher basal cortisol predicts verbal memory loss in postmenopausal women: Rancho Bernardo Study. J Am Geriatr Soc 48:1655-1658.

Haber SN, Knutson B (2010) The reward circuit: linking primate anatomy and human imaging. Neuropsychopharmacology 35:426.

Halpern DF (2000) Sex differences in cognitive abilities, Ed 3. New York, NY: Psychology Press.

Hampson E (2002) Sex difference in human brain and cognition: the influence of sex steroids in early and adult life. In: Behavioral endocrinology, pp 579-628. Cambridge, MA: MIT Press.

Heinzel S, Metzger FG, Ehlis A-C, Korell R, Alboji A, Haeussinger FB, Hagen K, Maetzler W, Eschweiler GW, Berg D, Fallgatter AJ (2013) Aging-related cortical reorganization of verbal fluency processing: a functional near-infrared spectroscopy study. Neurobiol Aging 34:439-450.

Hopkins WD (1999) On the other hand: statistical issues in the assessment and interpretation of hand preference data in nonhuman primates. Int J Primatol 20:851-866.

Humphries MD, Gurney K (2008) Network "small-world-ness": a quantitative method for determining canonical network equivalence. PLoS One 3:e0002051.

Ingalhalikar M, Smith A, Parker D, Satterthwaite TD, Elliott M. a, Ruparel K, Hakonarson H, Gur RE, Gur RC, Verma R (2014) Sex differences in the structural connectome of the human brain. Proc Natl Acad Sci USA 111:823-828.

Izquierdo A (2004) Bilateral orbital prefrontal cortex lesions in rhesus monkeys disrupt choices guided by both reward value and reward contingency. J Neurosci 24:7540-7548.

Izquierdo A, Brigman JL, Radke AK, Rudebeck PH, Holmes A (2017) The neural basis of reversal learning: an updated perspective. Neuroscience 345:12-26.

Jackson SAW, Horst NK, Axelsson SFA, Horiguchi N, Cockcroft GJ, Robbins TW, Roberts AC (2019) Selective role of the putamen in serial reversal learning in the marmoset. Cereb Cortex 29:447-460.

Jenkinson M, Bannister P, Brady M, Smith S (2002) Improved optimization for the robust and accurate linear registration and motion correction of brain images. Neuroimage 17:825-841.

Joel D, Tarrasch R (2014) On the mis-presentation and misinterpretation of gender-related data: the case of Ingalhalikar's human connectome study. Proc Natl Acad Sci USA 111:E637-E637.

Johnson EO, Kamilaris TC, Carter CS, Calogero AE, Gold PW, Chrousos GP (1996) The biobehavioral consequences of psychogenic stress in a small, social primate (Callithrix jacchus jacchus). Biol Psychiatry 40:317-337.

Kalmijn S, Launer LJ, Stolk RP, de Jong FH, Pols HA, Hofman A, Breteler MM, Lamberts SW (1998) A prospective study on cortisol, dehydroepiandrosterone sulfate, and cognitive function in the elderly. J Clin Endocrinol Metab 83:3487-3492.

Kannurpatti SS, Rypma B, Biswal BB (2012) Prediction of taskrelated BOLD $\mathrm{fMRI}$ with amplitude signatures of resting-state fMRI. Front Syst Neurosci 6:7.

Kimura D (1992) Sex differences in the brain. Sci Am 267:118-125. Korol DL, Malin EL, Borden KA, Busby RA, Couper-Leo J (2004) Shifts in preferred learning strategy across the estrous cycle in female rats. Horm Behav 45:330-338. 
LaClair M, Lacreuse A (2016) Reversal learning in gonadectomized marmosets with and without hormone replacement: are males more sensitive to punishment? Anim Cogn 19:619-630.

Lacreuse A, Chang J, Metevier CM, Laclair M, Meyer JS, Ferris CM (2014) Oestradiol modulation of cognition in adult female marmosets (Callithrix jacchus). J Neuroendocrinol 26:296-309.

Lacreuse A, Moore CM, LaClair M, Payne L, King JA (2018) Glutamine/glutamate $(\mathrm{Glx})$ concentration in prefrontal cortex predicts reversal learning performance in the marmoset. Behav Brain Res 346:11-15.

Lee BK, Glass TA, McAtee MJ, Wand GS, Bandeen-Roche K, Bolla KI, Schwartz BS (2007) Associations of salivary cortisol with cognitive function in the Baltimore memory study. Arch Gen Psychiatry 64:810-818.

Levine S, Vasilyeva M, Lourenco SF, Newcombe NS, Huttenlocher J (2005) Socioeconomic status modifies the sex difference in spatial skill. Psychol Sci 16:841-845.

Lippa RA, Collaer ML, Peters M (2010) Sex differences in mental rotation and line angle judgments are positively associated with gender equality and economic development across 53 nations. Arch Sex Behav 39:990-997.

Liu C, Ye FQ, Yen CCC, Newman JD, Glen D, Leopold DA, Silva AC (2018) A digital 3D atlas of the marmoset brain based on multimodal MRI. Neuroimage 169:106-116.

Liu C, Yen CC, Szczupak D, Ye FQ, Leopold DA, Silva AC (2019) Anatomical and functional investigation of the marmoset default mode network. Nat Commun 10:1975.

Liu JV, Hirano Y, Nascimento GC, Stefanovic B, Leopold DA, Silva AC (2013) fMRI in the awake marmoset: somatosensory-evoked responses, functional connectivity, and comparison with propofol anesthesia. Neuroimage 78:186-195.

Lurie DJ, Kessler D, Bassett DS, Betzel RF, Breakspear M, Keilholz S, Kucyi A, Liégeois R, Lindquist MA, Randal Mclntosh A, Calhoun VD (2018) On the nature of resting $f M R I$ and time-varying functional connectivity. Advance online publication. Retrieved December 24, 2018. doi:10.31234/osf.io/xtzre.

Machado CJ, Bachevalier J (2007) The effects of selective amygdala, orbital frontal cortex or hippocampal formation lesions on reward assessment in nonhuman primates. Eur J Neurosci 25:2885-2904.

Marshall JWB, Ridley RM, Baker HF, Hall LD, Carpenter TA, Wood NI (2003) Serial MRI, functional recovery, and long-term infarct maturation in a non-human primate model of stroke. Brain Res Bull 61:577-585

McAlonan K, Brown VJ (2003) Orbital prefrontal cortex mediates reversal learning and not attentional set shifting in the rat. Behav Brain Res 146:97-103.

Mennes M, Kelly C, Zuo X-N, Di Martino A, Biswal BB, Castellanos FX, Milham MP (2010) Inter-individual differences in resting-state functional connectivity predict task-induced BOLD activity. Neuroimage 50:1690-1701.

Miles RC (1957) Delayed-response learning in the marmoset and the macaque. J Comp Physiol Psychol 50:352-355.

Miller CT (2017) Why marmosets? Dev Neurobiol 77:237-243.

Miller DI, Halpern DF (2014) The new science of cognitive sex differences. Trends Cogn Sci 18:37-45.

Miyachi S, Hikosaka O, Lu X (2002) Differential activation of monkey striatal neurons in the early and late stages of procedural learning. Exp Brain Res 146:122-126.

Munro CA, Winicki JM, Schretlen DJ, Gower EW, Turano KA, Muñoz B, Keay L, Bandeen-Roche K, West SK (2012) Sex differences in cognition in healthy elderly individuals. Neuropsychol Dev Cogn B Aging Neuropsychol Cogn 19:759-768.

Murre JMJ, Janssen SMJ, Rouw R, Meeter M (2013) The rise and fall of immediate and delayed memory for verbal and visuospatial information from late childhood to late adulthood. Acta Psychol (Amst) 142:96-107.

Nagahama Y, Okada T, Katsumi Y, Hayashi T, Yamauchi H, Oyanagi C, Konishi J, Fukuyama H, Shibasaki H (2001) Dissociable mechanisms of attentional control within the human prefrontal cortex. Cereb Cortex 11:85-92.
Newman MEJ (2003) Properties of highly clustered networks. Phys Rev E 68:26121.

Newman MEJ, Girvan M (2004) Finding and evaluating community structure in networks. Phys Rev E Stat Nonlin Soft Matter Phys 69:26113

Okano H, Hikishima K, Iriki A, Sasaki E (2012) The common marmoset as a novel animal model system for biomedical and neuroscience research applications. Semin Fetal Neonatal Med 17:336340.

Overman WH (2004) Sex differences in early childhood, adolescence, and adulthood on cognitive tasks that rely on orbital prefrontal cortex. Brain Cogn 55:134-147.

Owen AM, Roberts AC, Polkey CE, Sahakian BJ, Robbins TW (1991) Extra-dimensional versus intra-dimensional set shifting performance following frontal lobe excisions, temporal lobe excisions or amygdalo-hippocampectomy in man. Neuropsychologia 29:9931006.

Pearce PC, Crofts HS, Muggleton NG, Scott EAM (1998) Concurrent monitoring of EEG and performance in the common marmoset: a methodological approach. Physiol Behav 63:591-599.

Phillips KA, Ross CN, Spross J, Cheng CJ, Izquierdo A, Biju KC, Chen C, Li S, Tardif SD (2017) Behavioral phenotypes associated with MPTP induction of partial lesions in common marmosets (Callithrix jacchus). Behav Brain Res 325:51-62.

Pietrzak RH, Laws SM, Lim YY, Bender SJ, Porter T, Doecke J, Ames D, Fowler C, Masters CL, Milicic L, Rainey-Smith S, Villemagne VL, Rowe CC, Martins RN, Maruff P; Australian Imaging, Biomarkers and Lifestyle Research Group (2017) Plasma Cortisol, brain amyloid- $\beta$, and cognitive decline in preclinical Alzheimer's Disease: a 6-year prospective cohort study. Biol Psychiatry Cogn Neurosci Neuroimaging 2:45-52.

Prins NW, Pohlmeyer EA, Debnath S, Mylavarapu R, Geng S, Sanchez JC, Rothen D, Prasad A (2017) Common marmoset (Callithrix jacchus) as a primate model for behavioral neuroscience studies. $\mathrm{J}$ Neurosci Methods 284:35-46.

Ridley RM, Haystead TAJ, Baker HF (1981) An analysis of visual object reversal learning in the marmoset after amphetamine and haloperidol. Pharmacol Biochem Behav 14:345-351.

Ritchie SJ, Cox SR, Shen X, Lombardo MV, Reus LM, Alloza C Harris MA, Alderson HL, Hunter S, Neilson E, Liewald DCM, Auyeung B, Whalley HC, Lawrie SM, Gale CR, Bastin ME, Mclntosh AM, Deary IJ (2018) Sex differences in the adult human brain: evidence from 5216 UK biobank participants. Cereb Cortex 28: 2959-2975.

Robbins TW, James M, Owen AM, Sahakian BJ, Mclnnes L, Rabbitt P (1994) Cambridge neuropsychological test automated battery (CANTAB): a factor analytic study of a large sample of normal elderly volunteers. Dement Geriatr Cogn Disord 5:266-281.

Roberts AC, Robbins TW, Everitt BJ (1988) The effects of intradimensional and extradimensional shifts on visual discrimination learning in humans and non-human primates. Q J Exp Psychol B 40:321-341.

Rubinov M, Sporns O (2010) Complex network measures of brain connectivity: uses and interpretations. Neuroimage 52:10591069.

Rumbaugh DM, Jeeves MA (1966) A comparison of two discrimination-reversal indices intended for use with diverse groups of organisms. Psychon Sci 6:1-2.

Rygula R, Walker SC, Clarke HF, Robbins TW, Roberts AC (2010) Differential contributions of the primate ventrolateral prefrontal and orbitofrontal cortex to serial reversal learning. J Neurosci 30: 14552-14559.

Sala-Llonch R, Peña-Gómez C, Arenaza-Urquijo EM, Vidal-Piñeiro D, Bargalló N, Junqué C, Bartrés-Faz D (2012) Brain connectivity during resting state and subsequent working memory task predicts behavioural performance. Cortex 48:1187-1196.

Saltzman W, Prudom SL, Schultz-Darken NJ, Wittwer DJ, Abbott DH (2004) Social suppression of cortisol in female marmoset monkeys: role of circulating ACTH levels and glucocorticoid negative feedback. Psychoneuroendocrinology 29:141-161. 
Saramäki J, Kivelä M, Onnela JP, Kaski K, Kertész J (2007) Generalizations of the clustering coefficient to weighted complex networks. Phys Rev E Stat Nonlin Soft Matter Phys 75:027105.

Satterthwaite TD, Wolf DH, Roalf DR, Ruparel K, Erus G, Vandekar S, Gennatas ED, Elliott MA, Smith A, Hakonarson H, Verma R, Davatzikos C, Gur RE, Gur RC (2015) Linked sex differences in cognition and functional connectivity in youth. Cereb Cortex 25: 2383-2394.

Schoenberg HL, Sola EX, Seyller E, Kelberman M, Toufexis DJ (2019) Female rats express habitual behavior earlier in operant training than males. Behav Neurosci 133:110-120.

Shams WM, Sanio C, Quinlan MG, Brake WG (2016) $17 \beta$-Estradiol infusions into the dorsal striatum rapidly increase dorsal striatal dopamine release in vivo. Neuroscience 330:162-170.

Silva AC, Liu JV, Hirano Y, Leoni RF, Merkle H, Mackel JB, Zhang XF, Nascimento GC, Stefanovic B (2011) Longitudinal functional magnetic resonance imaging in animal models. Methods Mol Biol 711:281-302.

Smith SM (2002) Fast robust automated brain extraction. Hum Brain Mapp 17:143-155.

Smith TE, French JA (1997) Psychosocial stress and urinary cortisol excretion in marmoset monkeys (Callithrix kuhli). Physiol Behav 62:225-232.

Solomon SG, Rosa MGP (2014) A simpler primate brain: the visual system of the marmoset monkey. Front Neural Circuits 8:96.
Spinelli S, Pennanen L, Dettling AC, Feldon J, Higgins GA, Pryce CR (2004) Performance of the marmoset monkey on computerized tasks of attention and working memory. Cogn Brain Res 19:123-137.

Stevenson MF (1977) The common marmoset (Callithrix jacchus jacchus) as a model for ethological research. Lab Anim Sci 27: 895-900.

Takemoto A, Miwa M, Koba R, Yamaguchi C, Suzuki H, Nakamura K (2015) Individual variability in visual discrimination and reversal learning performance in common marmosets. Neurosci Res 93: 136-143.

Tunç B, Solmaz B, Parker D, Satterthwaite TD, Elliott MA, Calkins ME, Ruparel K, Gur RE, Gur RC, Verma R (2016) Establishing a link between sex-related differences in the structural connectome and behaviour. Philos Trans R Soc B Biol Sci 371: 20150111.

Voyer D, Voyer S, Bryden MP (1995) Magnitude of sex differences in spatial abilities: a meta-analysis and consideration of critical variables. Psychol Bull 117:250-270.

Watts DJ, Strogatz SH (1998) Collective dynamics of 'small-world' networks. Nature 393:440.

Xia M, Wang J, He Y (2013) BrainNet viewer: a network visualization tool for human brain connectomics. PLoS One 8:68910.

Zou Q, Ross TJ, Gu H, Geng X, Zuo XN, Hong LE, Gao JH, Stein EA, Zang YF, Yang Y (2013) Intrinsic resting-state activity predicts working memory brain activation and behavioral performance. Hum Brain Mapp 34:3204-3215. 